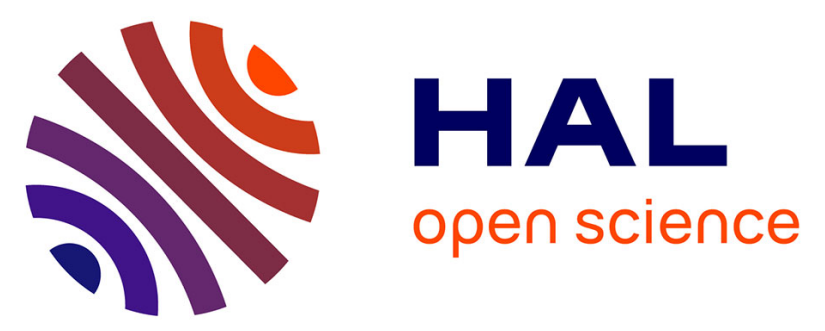

\title{
Thermo-oxidative degradation of additive free polyethylene. Part I. Analysis of chemical modifications at molecular and macromolec-ular scales
}

\author{
Manuela da Cruz, Laëtitia van Schoors, Karim Benzarti, Xavier Colin
}

\section{- To cite this version:}

Manuela da Cruz, Laëtitia van Schoors, Karim Benzarti, Xavier Colin. Thermo-oxidative degradation of additive free polyethylene. Part I. Analysis of chemical modifications at molecular and macromolec-ular scales. Journal of Applied Polymer Science, 2016, 133 (18), pp.Article number 43287. 10.1002/app.43287 . hal-02291131

\section{HAL Id: hal-02291131 \\ https://hal.science/hal-02291131}

Submitted on 18 Sep 2019

HAL is a multi-disciplinary open access archive for the deposit and dissemination of scientific research documents, whether they are published or not. The documents may come from teaching and research institutions in France or abroad, or from public or private research centers.
L'archive ouverte pluridisciplinaire $\mathbf{H A L}$, est destinée au dépôt et à la diffusion de documents scientifiques de niveau recherche, publiés ou non, émanant des établissements d'enseignement et de recherche français ou étrangers, des laboratoires publics ou privés. 


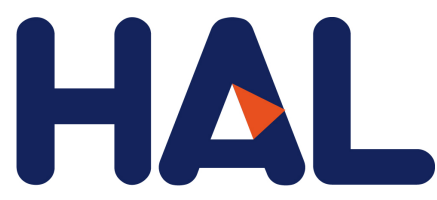

archives-ouvertes

\title{
Thermo-oxidative degradation of additive free polyethylene. Part I. Analysis of chemical modifications at molecular and macromolecular scales
}

\author{
Manuela da Cruz, Laëtitia van Schoors, Karim Benzarti, Xavier Colin
}

\section{- To cite this version:}

Manuela da Cruz, Laëtitia van Schoors, Karim Benzarti, Xavier Colin. Thermo-oxidative degradation of additive free polyethylene. Part I. Analysis of chemical modifications at molecular and macromolecular scales. JOURNAL OF APPLIED POLYMER SCIENCE, 2016, Volume 133, Issue 18, pp.Article number 43287. hal-02291131

\section{HAL Id: hal-02291131 \\ https://hal.archives-ouvertes.fr/hal-02291131}

Submitted on 18 Sep 2019

HAL is a multi-disciplinary open access archive for the deposit and dissemination of scientific research documents, whether they are published or not. The documents may come from teaching and research institutions in France or abroad, or from public or private research centers.
L'archive ouverte pluridisciplinaire HAL, est destinée au dépôt et à la diffusion de documents scientifiques de niveau recherche, publiés ou non, émanant des établissements d'enseignement et de recherche français ou étrangers, des laboratoires publics ou privés. 


\title{
Thermo-oxidative degradation of additive free polyethylene. Part I. Analysis of chemical modifications at molecular and macromolecular scales
}

\author{
Manuela Da Cruz, ${ }^{1,2}$ Laetitia Van Schoors, ${ }^{1}$ Karim Benzarti, ${ }^{1}$ Xavier Colin ${ }^{2}$ \\ ${ }^{1}$ Université Paris-Est, IFSTTAR, MAST, CPDM, 14-20 Boulevard Newton Cité Descartes, Champs Sur Marne, \\ 77447 Marne-la-Vallée Cedex 2, Paris, France \\ ${ }^{2}$ Arts Et Métiers ParisTech, PIMM (UMR CNRS 8006), 151 Boulevard De L'hôpital, Paris 75013, France \\ Correspondence to: X. Colin (E-mail: xavier.colin@ensam.eu)
}

\begin{abstract}
The effects of thermal oxidation on the molecular and macromolecular structures of additive free PE were investigated between $100{ }^{\circ} \mathrm{C}$ and $140{ }^{\circ} \mathrm{C}$ in air in order to tentatively establish non-empirical structure/property relationships. In the first part, the changes in $\mathrm{POOH}$ concentration were assessed by three different analytical methods: iodometry, modulated differential scanning calorimetry, and Fourier transform infrared (FTIR) spectrophotometry after $\mathrm{SO}_{2}$ treatment. All these methods provided very similar results until the end of the induction period, after which iodometry overestimated strongly POOH concentration because it titrates also other chemical species formed at high conversion ratios, namely double bonds. In parallel, the changes in carbonyl group concentration were determined by FTIR spectrophotometry after $\mathrm{NH}_{3}$ treatment. As the accumulation kinetics of ketones, aldehydes, and carboxylic acids were closely interrelated, the question of their actual formation mechanisms in the current thermal oxidation mechanistic scheme was raised. An alternative reaction pathway was proposed for the bimolecular decomposition of $\mathrm{POOH}$. In the second part, the corresponding changes in weight and number average molecular masses were monitored by high temperature gel permeation chromatography equipped with a triple detection technology. As both quantities decreased dramatically from the beginning of exposure and their ratio $M_{w} / M_{n}$ tends toward the asymptotic value of 2 and it was concluded that a "pure" chain scission process operated. Finally, as the number of chain scissions perfectly correlates, the concentration sum of aldehydes and their oxidation products (i.e., carboxylic acids), it was also concluded that these carbonyl groups result exclusively from the $\beta$ scission of alkoxy radicals.
\end{abstract}

KEYWORDS: ageing; degradation; kinetics; polyolefins

\section{INTRODUCTION}

Polyethylene (PE) is commonly used in civil engineering and building applications due to its low cost, easy processability, good barrier properties, and chemical resistance. However, environmental factors such as ultraviolet (UV) radiation and seasonal temperature variations can cause its chemical degradation and, ultimately, its embrittlement at long term. ${ }^{1,2}$ The incorporation of antioxidants during melt processing is, thus, necessary to delay the onset of oxidation and increase the lifetime. ${ }^{3}$ However, in service conditions, antioxidants can be physically lost by water extraction and/or evaporation, but also consumed by chemical reactions. ${ }^{4}$ When the polymer matrix is no longer sufficiently protected, the oxidation rate increases suddenly ${ }^{5}$ and thenceforth, induces macromolecular and morphological changes leading to a catastrophic decay in fracture properties. $^{6}$

Therefore, the study of PE durability is a multidisciplinary problem which requires addressing scientific challenges at different structural scales. At the lowest (i.e., molecular) scale, stabilization and oxidation mechanisms must be better understood in order to establish the most realistic mechanistic scheme as possible and deduce a non-empirical mathematical expression for the oxidation rate.

At the highest (i.e., macroscopic) scale, the changes in mechanical properties versus exposure time must be analyzed in detail 
in order to identify what quantities are the most sensitive to oxidative degradation and to define, on this basis, the most relevant end-of-life criterion for the application under consideration. In the case of a semi-crystalline polymer having its amorphous phase in rubbery state, such as polyolefins, it is usual to select the ultimate elongation for describing the sharp ductile/brittle transition because this property varies monotonically with exposure time (contrarily to tensile strength). ${ }^{7}$ Thus, the conventional end-of-life criterion is a loss of $50 \%$ of the initial value of the ultimate elongation. ${ }^{8}$
At intermediary (i.e., macromolecular and morphological) scales, embrittlement processes must be clearly evidenced and elucidated. In most cases of PE oxidation, random chain scissions largely predominate over crosslinking ${ }^{9-11}$ and induce chemi-crystallization. ${ }^{12}$ The conversion ratio of both processes is, thus, closely related to the changes in the molecular mass distribution. $^{12}$

From this rapid literature overview, it appears that the ideal approach for lifetime prediction of PE could be summarized by the following causal chain:

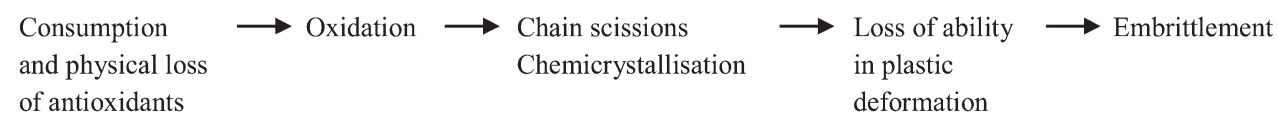

At this stage of investigations, important efforts are still needed for determining all the structural variables playing a key role in this causal chain, but also for establishing non-empirical connections between these variables, that is, structure/property relationships.

The present article is focused on the thermal oxidation between $100{ }^{\circ} \mathrm{C}$ and $140{ }^{\circ} \mathrm{C}$ in air of additive free $\mathrm{PE}$ at both molecular and macromolecular scales. It must be recalled that thermal oxidation is a radical chain reaction initiated by the decomposition of its main propagation product: the hydroperoxide group $(\mathrm{POOH})$, which is also the most instable product. $^{1,13}$ Indeed, the dissociation energy of its $\mathrm{O}-\mathrm{O}$ bond is about $150 \mathrm{~kJ} / \mathrm{mol}$, against more than $325 \mathrm{~kJ} / \mathrm{mol}$ for all other chemical bonds composing the polymer chain (including structural defects such as allylic $\mathrm{C}-\mathrm{H}$ bonds). ${ }^{14}$ In its simplest form (i.e., in oxygen excess and in the absence of thermal and photochemical stabilizers), this reaction can be written such as: ${ }^{13}$

Initiation:

(Iu) $\mathrm{POOH} \rightarrow 2 \mathrm{P}^{\circ}+\gamma_{1} \mathrm{P}^{\mathrm{H}}=\mathrm{O}+\left(1-\gamma_{1}\right) \mathrm{P}-\mathrm{OH}+\gamma_{S} S$

$+\mathrm{H}_{2} \mathrm{O}\left(k_{1 u}\right)$

(Ib) $2 \mathrm{POOH} \rightarrow \mathrm{P}^{\circ}+\mathrm{PO}_{2}+\gamma_{1} \mathrm{P}^{\mathrm{H}}=\mathrm{O}+\left(1-\gamma_{1}\right) \mathrm{P}-\mathrm{OH}$

$+\gamma_{S} \mathrm{~S}+\mathrm{H}_{2} \mathrm{O}\left(k_{1 b}\right)$

Propagation:

$(\mathrm{II}) \mathrm{P}^{\circ}+\mathrm{O}_{2} \rightarrow \mathrm{PO}_{2}^{\circ}\left(k_{2}\right)$

$(\mathrm{III}) \mathrm{PO}_{2}{ }^{\circ}+\mathrm{PH} \rightarrow \mathrm{POOH}+\mathrm{P}^{\circ}\left(k_{3}\right)$

Bimolecular recombination:

(VIa) $\mathrm{PO}_{2}{ }^{\circ}+\mathrm{PO}_{2}{ }^{\circ} \rightarrow\left[\mathrm{PO}^{\circ}{ }^{\circ} \mathrm{OP}\right]_{\mathrm{cage}}+\mathrm{O}_{2}\left(k_{6 a}\right)$

$(\mathrm{VIb})\left[\mathrm{PO}^{\circ}{ }^{\circ} \mathrm{OP}\right]_{\text {cage }} \rightarrow \mathrm{POOP}+\mathrm{X}\left(k_{6 b}\right)$

$(\mathrm{VIc})\left[\mathrm{PO}^{\circ}{ }^{\circ} \mathrm{OP}\right]_{\text {cage }} \rightarrow \mathrm{P}=\mathrm{O}+\mathrm{P}-\mathrm{OH}\left(k_{6 c}\right)$

(VId) $\left[\mathrm{PO}^{\circ}{ }^{\circ} \mathrm{OP}\right]_{\text {cage }} \rightarrow 2 \mathrm{P}^{\circ}+2 \gamma_{1} \mathrm{P}^{\mathrm{H}}=\mathrm{O}$

$+2\left(1-\gamma_{1}\right) \mathrm{P}-\mathrm{OH}+2 \gamma_{S} \mathrm{~S}\left(k_{6 d}\right)$

where $\mathrm{PH}, \mathrm{P}^{\circ}, \mathrm{PO}_{2}^{\circ}, \mathrm{PO}^{\circ}, \mathrm{POOH}, \mathrm{POOP}, \mathrm{P}^{\mathrm{H}}=\mathrm{O}, \mathrm{P}=\mathrm{O}, \mathrm{P}-\mathrm{OH}$, $\mathrm{S}$, and $\mathrm{X}$ accounts, respectively, for secondary $\mathrm{C}-\mathrm{H}$ groups (i.e., methylene groups), alkyl, peroxy and alkoxy radicals, hydroperoxides, dialkyl peroxides, aldehydes, ketones, alcohols, chain scissions, and crosslink nodes. $k_{i}$ are elementary rate constants of the chemical events under consideration. $\gamma_{S}$ is the yield of $\beta$ scission (leading to aldehydes), irrespectively of the molecularity of the initiation reaction, in competition with hydrogen abstraction (leading to alcohols).

From a practical point of view, it is more convenient to consider an apparent yield $\gamma_{1}$ for the formation of aldehydes owing to the high difficulty to titrate them accurately by common spectrochemical methods, in particular by Fourier transform infrared (FTIR) analysis. Indeed, their titration requires extracting their elementary contribution from the composite absorption band relative to all types of carbonyl groups. However, deconvolution methods are in general based on too simple mathematical functions (frequently of Gaussian's type) of which the actual representativeness is highly questionable. ${ }^{1}$ Moreover, the molar extinction coefficients of carbonyl groups are in general poorly known. As an example, they would be ranged between 155 and $270 \mathrm{~L} / \mathrm{mol} /$ cm for aldehydes. ${ }^{15,16}$

The most relevant molecular variables, from a kinetic modeling point of view, are oxygen uptake and hydroperoxides concentration because their respective changes versus exposure time can be accurately simulated without the use of additional parameters than the previous rate constants. ${ }^{17-19}$ Oxygen uptake can be easily measured by manometric methods. ${ }^{20-23}$ These latter have recently reached a remarkable degree of sensitivity. ${ }^{24}$ In contrast, the titration of hydroperoxides is more complicated and still controversial. Indeed, these chemical species are not only thermolabile, but are also formed in very low concentrations in polyolefin matrices (typically $\ll 1 \mathrm{~mol} / \mathrm{L}$ ). Nevertheless, three main titration methods of hydroperoxides are reported in the literature:

- The spectrochemical approach consists in the determination of the concentration of reaction products by FTIR spectrophotometry after $\mathrm{SO}_{2}\left(\mathrm{SO}_{2}\right.$-FTIR), ${ }^{25-28} \mathrm{NO}$ (NO-FTIR), ${ }^{29-32}$ or $\mathrm{Fe}^{2+}$ treatment $\left(\mathrm{Fe}^{2+}\right.$-FTIR). ${ }^{33}$ 
- The chemical approach consists in the titration of hydroperoxides by iodometry. ${ }^{33-35}$

- And the thermodynamical approach ${ }^{33,36,37}$ is based on the measurement of the thermal decomposition enthalpy of hydroperoxides by differential scanning calorimetry (DSC) under nitrogen flow.

For the two first methods, significant discrepancies between the experimental results are reported in the literature. In the case of $\mathrm{SO}_{2}$-FTIR, these discrepancies are presumably due to different ways to process experimental data. As an example, Tireau et $a .^{27}$ used the absorption band characteristic to the reaction products between $\mathrm{POOH}$ and $\mathrm{SO}_{2}$ (i.e., hydrosulfates) at $1042 \mathrm{~cm}^{-1}$ and a molar extinction coefficient of $470 \mathrm{~L} / \mathrm{mol} / \mathrm{cm}$ to estimate the $\mathrm{POOH}$ concentration. It can be noticed that other characteristic bands of hydrosulfates could have been chosen for making this quantification, for instance at 920 and $1195 \mathrm{~cm}^{-1} .^{25,28}$ In contrast, Gardette et al. ${ }^{35}$ and Richaud et al. $^{26}$ preferred to use the decrease in the absorption band of hydroxyls around $3400 \mathrm{~cm}^{-1}$ after total conversion of hydroperoxides into hydrosulfates by $\mathrm{SO}_{2}$. They made two assumptions: (i) $\mathrm{SO}_{2}$ treatment does not create new $\mathrm{OH}$ groups; (ii) alcohols and hydroperoxides have almost the same molar extinction coefficient (i.e., $75 \mathrm{~L} / \mathrm{mol} / \mathrm{cm}$ ).

In the case of iodometry, these discrepancies are presumably due to changes in the operating conditions of experimental protocols, especially in the reflux times of samples in sodium iodide solution, but also to different ways to filter the solution after refluxing. Some authors maintained the sample in solution for a sufficiently long time in order to dissolve it completely and thus, avoid diffusion problems into the sample thickness. ${ }^{33}$ As an example, according to Richaud et al., ${ }^{34}$ in the case of thermo-oxidized polypropylene (PP) films of $70 \mu \mathrm{m}$ thickness, the reaction time needed for converting all hydroperoxides into alcohols is $30 \mathrm{~min}$. In contrast, according to Carlsson et al. ${ }^{28}$ in the case of photo- and thermo-oxidized PE and PP films of 25 $\mu \mathrm{m}$ thickness, a reflux time of $5 \mathrm{~min}$ is enough for converting more than $95 \mathrm{~mol} \%$ of $\mathrm{POOH}$ groups. However, for thicker samples having undergone an oxidation under $\gamma$ irradiation (which may then be partially cross-linked), this time should be increased to $60 \mathrm{~min}$. In the case of radio-oxidized PE films of $120 \mu \mathrm{m}$ thickness, the same authors found a good correlation between the $\mathrm{POOH}$ concentrations determined by iodometry and FTIR measurements at $3400 \mathrm{~cm}^{-1}$. They also reported that some samples (especially photo-oxidized ones) had generated colloidal suspensions after refluxing, presumably due to an extraction of the small macromolecular segments formed by chain scissions. To avoid such a complication, they suggested filtering the solution under a nitrogen atmosphere through a filter of $5 \mu \mathrm{m}$ pore size, just before performing spectrophotometric measurements.

In contrast, in the case of DSC, experimental results are scarce and poorly scattered. The use of modulated (MDSC) instead of conventional DSC is justified when the melting endotherm of the crystalline lamellae is very close to or is overlapped with the decomposition exotherm of hydroperoxides. This is the case for instance for $\mathrm{PP}^{26,37}$
Each one of these three titration methods has advantages and drawbacks. According to Carlsson et al., ${ }^{32}$ those involving a chemical reaction in gas phase are the most reliable for identifying the functional groups, since they avoid the structural modifications (extraction of molecular additives and short macromolecular fragments, morphological restructuration of polymer matrix, etc.) that are usually observed in liquid phase. Thus, these authors ${ }^{32}$ showed that $\mathrm{SO}_{2}$-FTIR is a reliable method in the case of PE oxidation, but can lead to misleading results in the case of PP oxidation because of the formation of complex $\mathrm{POOH}$ compounds. In contrast, according to Jacobson, ${ }^{25} \mathrm{SO}_{2}$-FTIR would be a poorly reliable method due to the thermal instability of hydrosulfates. Thus, it may only provide semi-quantitative information on the spatial distribution of hydroperoxides in the polymer matrix by coloring the areas rich in hydroperoxides. Finally Gardette et al. $^{35}$ indicated that iodometry can only be used if hydroperoxides are thermally stable throughout the experiment duration, typically for temperatures lower than $80{ }^{\circ} \mathrm{C}$.

On the contrary, according to Ouldmetidji, ${ }^{36}$ MDSC would present many advantages compared with $\mathrm{SO}_{2}$-FTIR and iodometry. Easier and faster to use, it would be also more sensitive. Mallégol et $a l^{37}$ showed that the thermal decomposition enthalpy of hydroperoxides $\left(\Delta H_{\mathrm{POOH}}\right)$ is proportional to their concentration. These authors also mentioned that the $\mathrm{POOH}$ decomposition is followed by the bimolecular recombination of macro-radicals and their addition onto unsaturations, both chemical reactions inducing the crosslinking of the polymer matrix in the DSC cavity. Thereafter, Richaud et al. ${ }^{34}$ used the classical concepts of thermochemistry for expressing $\Delta H_{\mathrm{POOH}}$ as a linear combination of the dissociation energies of the different chemical bonds broken or formed during the $\mathrm{POOH}$ decomposition and the subsequent chemical events. In the case of thermo-oxidized $\mathrm{PP}$, the experimental determination of $\Delta \mathrm{H}_{\mathrm{POOH}}$ in the non-reversible MDSC signal was complicated by the overlapping of a narrow component of the melting endotherm, centered around $150{ }^{\circ} \mathrm{C}$, with the wide decomposition exotherm of hydroperoxides ranged between $90{ }^{\circ} \mathrm{C}$ and $200{ }^{\circ} \mathrm{C}$. After having shown that this component is too small to change the quasi-symmetric shape of the decomposition exotherm and thus, can be reasonably neglected, Richaud et al. found a good correlation between MDSC and iodometry. ${ }^{34}$ At last, Mallegol et $a .^{37}$ used MDSC to determine the molecularity of the $\mathrm{POOH}$ decomposition.

A large number of secondary molecular variables can be also used to check the validity of the proposed oxidation mechanistic scheme and the corresponding kinetic model, provided that assumptions are made on formation yields. Most authors mainly focused on carbonyl groups because these latter can be easily detected by FTIR spectrophotometry between 1680 and $1770 \mathrm{~cm}^{-1}$. Some authors used chemical derivatization methods for demonstrating the presence of various types of carbonyl groups and identifying them. These methods induce a significant shift along the wavenumber axis of the absorption bands of carbonyl groups after reaction with a gaseous reagent, usually ammoniac $\left(\mathrm{NH}_{3}\right)$ or sulfur tetrafluoride $\left(\mathrm{SF}_{4}\right)$. As an example, $\mathrm{NH}_{3}$ transforms carboxylic acids into carboxylates having a 
characteristic band around $1550 \mathrm{~cm}^{-1}$. This gas also transforms esters into primary amides absorbing within the 1620$1680 \mathrm{~cm}^{-1}$ range. In contrast, $\mathrm{SF}_{4}$ reacts with carboxylic acids to give acid fluorides absorbing within the $1810-1840 \mathrm{~cm}^{-1}$ range. As a result, these gaseous treatments allow also better monitoring the changes versus exposure time in the absorption bands of unreactive carbonyl groups such as: ketones, aldehydes, lactones, etc. Based on these results, Tireau et al. proposed to use the absorption bands of carbonyl groups before and after the total conversion of carboxylic acids and esters by $\mathrm{NH}_{3}$, but also the resulting absorption bands of carboxylates and primary amides, for estimating the concentration of all types of carbonyl groups formed during the photo- and thermo-oxidation of $\mathrm{PE}^{27}$

Pilichowski et al. ${ }^{31}$ recognized that these gaseous treatments are of undeniable interest from an analytical point of view, but also argued that they are only effective for thin polymer films of about $100 \mu \mathrm{m}$ thickness. According to Ollier-Dureault et al., ${ }^{38}$ Delor et al., ${ }^{39}$ and Maillot et al., ${ }^{40} \mathrm{SF}_{4}$ and $\mathrm{NH}_{3}$ treatments would lead to similar results, regardless of the operating conditions of experimental protocol or the way to exploit data.

Only a few authors examined the consequences of PE oxidation at the macromolecular scale. Two main processes were detected: random chain scissions and crosslinking. Chain scissions lead to a decrease in the weight and number average molecular masses (i.e., $M_{w}$ and $M_{n}$ ) and, when polydispersity index (PDI $=M_{w} /$ $M_{n}$ ) is initially higher than 2 , they also induce a narrowing of the molecular mass distribution. Indeed, in the case of a "pure" chain scission process, PDI tends progressively toward 2. In contrast, crosslinking leads to an increase in the average molecular masses and a widening of the molecular mass distribution. All these macromolecular modifications induce a significant change in the rheological properties, in particular in the melt viscosity.

In the case of PE thermal oxidation, the competition between both macromolecular processes is controversial. Indeed, according to Iring et al., ${ }^{41}$ Fayolle et al., ${ }^{42}$ and Tireau et al., 27 a "pure" chain scission process would operate since $M_{w}$ and PDI decrease sharply from the beginning of exposure. In contrast, according to Srivastava et al., ${ }^{43}$ crosslinking would equilibrate chain scissions in the early periods of exposure since the melt viscosity remains almost constant, while the ultimate elongation and gel fraction increase. Finally, according to Weon ${ }^{44}$ and Khabbaz et al., ${ }^{45}$ chain scissions would be largely predominant over crosslinking throughout the thermal exposure duration. The existence of a secondary crosslinking process would be attested by the increase in the thermal decomposition temperature or PDI.

The objectives of the present article are twofold. First of all, the reliability of the main titration methods of hydroperoxides, that is, $\mathrm{SO}_{2}$-FTIR, iodometry, and MDSC, will be investigated. Secondly, the changes in average molecular masses will be determined by high temperature gel permeation chromatography equipped with a triple detection technology (HT-GPC). The most interesting results will be presented and interpreted in the light of the concentration changes of $\mathrm{POOH}$, carbonyl species, and chain scissions. A peculiar attention will be paid on the possible correlations between the structural modifications taking place at both molecular and macromolecular scales.

\section{EXPERIMENTAL}

\section{Materials}

A medium density PE classified as PE80 and recommended for applications of pressure pipe and fittings was chosen for this study. The unstabilized and unfilled PE powder was supplied by Borealis Company. Films of about $100 \mu \mathrm{m}$ thickness were elaborated by compression molding with a Gibrite laboratory press under a pressure of $24 \mathrm{MPa}$ for $90 \mathrm{~s}$ at $190{ }^{\circ} \mathrm{C}$. This low value of thickness ensures a homogeneous oxidation in the whole sample thickness during thermal exposures in air up to temperatures of $200{ }^{\circ} \mathrm{C}$.

After processing, PE films were characterized by conventional laboratory techniques. Their main characteristics are: melting point $T_{m 0}=127.8{ }^{\circ} \mathrm{C} \pm 1.0{ }^{\circ} \mathrm{C}$, crystallinity ratio $X_{C 0}=53 \% \pm 3 \%$, density $\rho_{0}=0.935 \mathrm{~g} / \mathrm{cm}$, weight and number average molecular masses $M_{w 0}=120 \pm 15 \mathrm{~kg} / \mathrm{mol}$, and $M_{n 0}=8 \pm 2 \mathrm{~kg} / \mathrm{mol}$.

\section{Oxidative Ageing Conditions}

PE films were thermally aged below and above their initial melting point at the temperatures of $80^{\circ} \mathrm{C}, 90^{\circ} \mathrm{C}, 100{ }^{\circ} \mathrm{C}, 110{ }^{\circ} \mathrm{C}$, $120{ }^{\circ} \mathrm{C}$, and $140{ }^{\circ} \mathrm{C}$ in air-ventilated ovens regulated at $\pm 1{ }^{\circ} \mathrm{C}$.

\section{Experimental Methods}

PE films were regularly removed from ovens and cooled at room temperature in a desiccator containing silica-gel. After complete cooling, they were characterized by a series of complementary analytical methods in order to determine the resulting changes at both molecular and macromolecular scales.

FTIR Analysis. The course of oxidation was monitored by FTIR spectrophotometry in a transmittance mode. The IR spectra of virgin and thermo-oxidized PE films were determined with a Perkin-Elmer Frontier device within the $4000-400 \mathrm{~cm}^{-1}$ range by averaging the 32 scans obtained with a minimal resolution of $4 \mathrm{~cm}^{-1}$.

As previously observed by Tireau et al., ${ }^{27}$ oxidation leads to two main modifications in IR spectra (Figure 1):

- Between 3100 and $3700 \mathrm{~cm}^{-1}$, the sudden appearance and rapid increase of a broad absorption band centered around $3400 \mathrm{~cm}^{-1}$ and assigned to the stretching vibration of the $\mathrm{O}-\mathrm{H}$ bond of hydroperoxides, alcohols, and carboxylic acids.

- Between 1690 and $1760 \mathrm{~cm}^{-1}$, the sudden appearance and rapid increase of a narrower absorption band having a maximum at $1718 \mathrm{~cm}^{-1}$ and assigned to the stretching vibration of the $\mathrm{C}=\mathrm{O}$ bond of many potential carbonyl compounds in particular: aldehydes, ketones, carboxylic acids, esters, and lactones.

The identification of these different oxidation products and the determination of their elementary contribution to both composite absorption bands have required to couple FTIR spectrophotometry with chemical derivatization techniques, in particular with $\mathrm{SO}_{2}$ and $\mathrm{NH}_{3}$ treatments (see next section).

In IR spectra, oxidation also results in a slow growth of the small absorption bands located at 965,910 , and $888 \mathrm{~cm}^{-1}$ and, respectively, characteristic to vinylene, vinyl, and vinylidene 


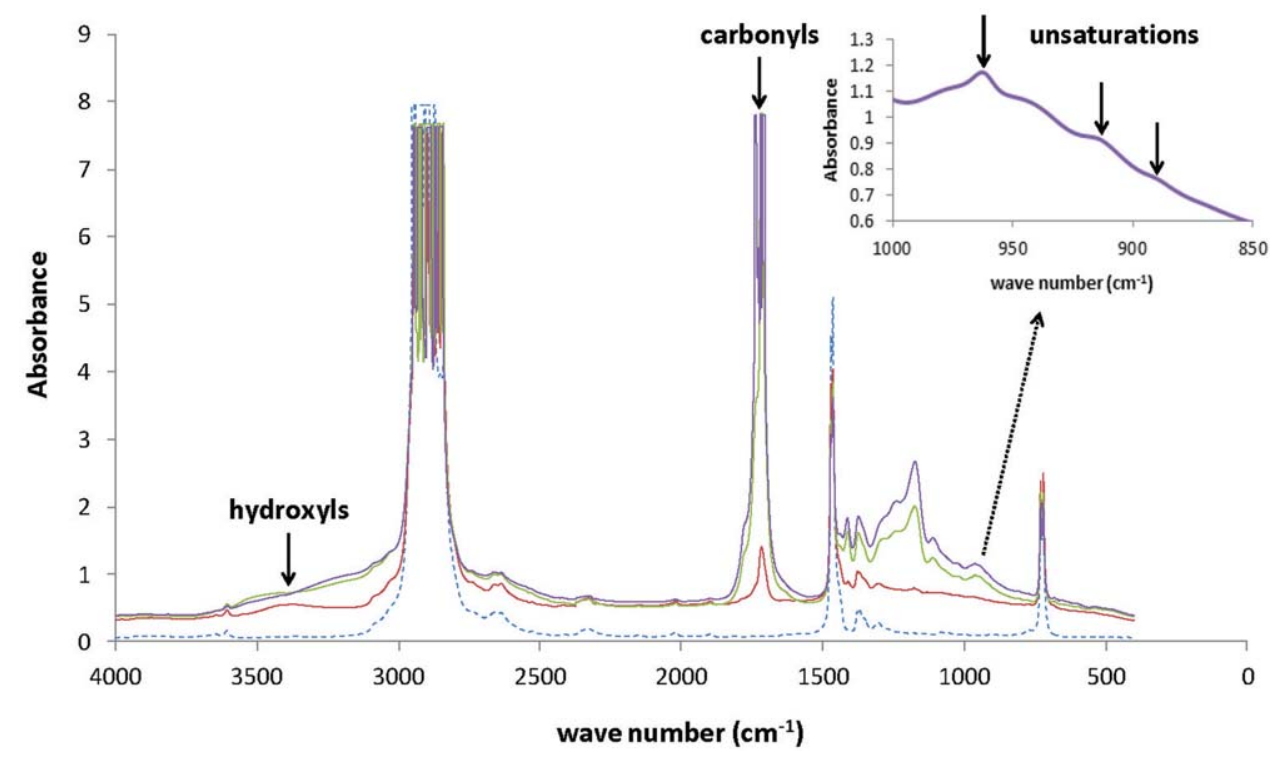

Figure 1. IR spectra of PE films before (dash lines) and after thermal exposure at $120{ }^{\circ} \mathrm{C}$ in air (solid lines). The inset shows an enlargement of the absorption regions characteristic to unsaturations. [Color figure can be viewed in the online issue, which is available at wileyonlinelibrary.com.]

unsaturations (see inset of Figure 1). These latter are initially present in low concentration as structural defects in the $\mathrm{PE}$ matrix. Their concentration changes versus exposure time was determined using the Beer-Lambert's law and taking values of molar extinction coefficient of 160,120 , and $100 \mathrm{~L} / \mathrm{mol} / \mathrm{cm}$, respectively. ${ }^{5,27,46,47}$

POOH Titration by $\mathrm{SO}_{2}$-FTIR. Virgin and thermo-oxidized PE films were exposed in a closed glass vessel at room temperature in an atmosphere fully saturated in sulfur dioxide for converting all hydroperoxides into hydrosulfates according to the following reaction ${ }^{25}$ :

$$
\mathrm{POOH}+\mathrm{SO}_{2} \rightarrow \mathrm{PSO}_{4} \mathrm{H}
$$

Gaseous $\mathrm{SO}_{2}$ was generated from a highly concentrated solution of $\mathrm{Na}_{2} \mathrm{SO}_{3}$ into $\mathrm{HCl}$ (typically $2500 \mathrm{~g} / \mathrm{L}$ ) deposited at the bottom of the vessel. After a period of one week, when reaction (1) was completed, the films were analyzed by FTIR spectrophotometry.

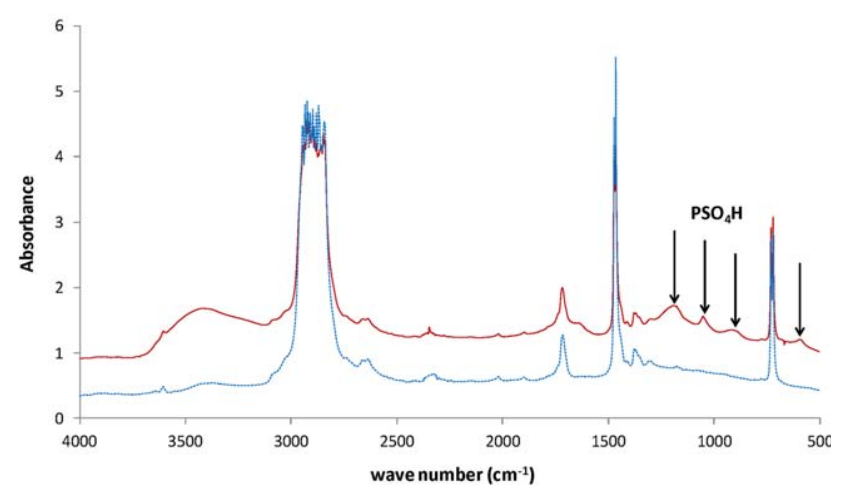

Figure 2. Example of IR spectra of thermo-oxidized PE films before (dash lines) and after (solid lines) $\mathrm{SO}_{2}$ treatment. Thermal ageing conditions: $100{ }^{\circ} \mathrm{C}$ in air for $216 \mathrm{~h}$. [Color figure can be viewed in the online issue, which is available at wileyonlinelibrary.com.]
Examples of IR spectra of thermo-oxidized PE films after and before $\mathrm{SO}_{2}$ treatment are presented in Figure 2. As expected, $\mathrm{SO}_{2}$ treatment leads to a significant reduction of the absorbance of the hydroxyl region (typically between 3100 and $3700 \mathrm{~cm}^{-1}$ ) and the formation of four new absorption bands characteristic to hydrosulfates at $1177 \mathrm{~cm}^{-1}(\mathrm{O}=\mathrm{S}=\mathrm{O}), 1050 \mathrm{~cm}^{-1}(\mathrm{~S}=\mathrm{O})$, $910 \mathrm{~cm}^{-1}(\mathrm{~S}-\mathrm{O}-\mathrm{C})$ and $593 \mathrm{~cm}^{-1}(\mathrm{C}-\mathrm{S})$. In agreement with the literature, ${ }^{25,28}$ the absorbance at $1050 \mathrm{~cm}^{-1}$ was chosen for calculating the $\mathrm{POOH}$ concentration with the Beer-Lambert's law taking a value of molar extinction coefficient of $155 \mathrm{~L} / \mathrm{mol} /$ $\mathrm{cm}$.

POOH Titration by Iodometry. Hydroperoxide concentration was also determined by iodometry which is, to date, the most commonly used analytical method for PP in the literature because of its assumed high reliability. ${ }^{27,31}$ This method is based on the reduction of the hydroperoxides by sodium iodide in an acidic medium according to the following reaction ${ }^{26,33,37}$ :

$$
\mathrm{POOH}+3 \mathrm{I}^{-}+2 \mathrm{H}^{+} \rightarrow \mathrm{POH}+\mathrm{I}_{3}{ }^{-}+\mathrm{H}_{2} \mathrm{O}
$$

Samples of about $10 \mathrm{mg}$ were immerged in a $7 \mathrm{~mL}$ solution consisting in a mixture of isopropanol and acetic acid solvents (10:1) in a two neck glass flask equipped with a bulb condenser. When refluxing, a $4 \mathrm{~mL}$ solution composed of sodium iodide dissolved into isopropanol (at a concentration of $200 \mathrm{~g} / \mathrm{L}$ ) was added with a syringe throughout the side neck. After a period of $15 \mathrm{~min}$, when reaction (2) was completed, the mixture was quenched up to room temperature with $25 \mathrm{~mL}$ of distilled water.

$\mathrm{I}_{3}^{-}$ions were titrated by UV spectrophotometry at $355 \mathrm{~nm}$ with a Perkin-Elmer Lambda 35 device. Their concentration was calculated with the Beer-Lambert's law taking a value of molar extinction coefficient of $25,000 \mathrm{~L} / \mathrm{mol} / \mathrm{cm}$. The $\mathrm{POOH}$ concentration was then deduced by the following equation: 


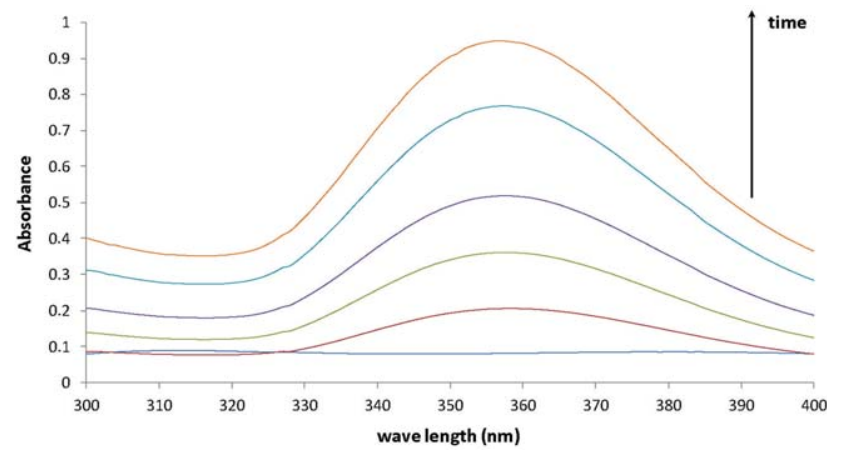

Figure 3. Examples of UV spectra of virgin and thermo-oxidized PE films after sodium iodide treatment. Thermal ageing conditions: $100{ }^{\circ} \mathrm{C}$ in air for $216 \mathrm{~h}$. [Color figure can be viewed in the online issue, which is available at wileyonlinelibrary.com.]

$$
[\mathrm{POOH}]=\frac{I_{3}^{-} \times V_{\text {solution }}}{m_{\mathrm{PE}}} \times \rho_{\mathrm{PE}}
$$

where $V_{\text {solution }}$ is the volume of the solution, $m_{\mathrm{PE}}$ is the mass of the PE film, and $\rho_{\mathrm{PE}}$ is the PE density.

Examples of UV spectra of virgin and thermo-oxidized PE films after sodium iodide treatment are presented in Figure 3. One observes clearly an increase in the absorption band at $355 \mathrm{~nm}$ with the exposure time at $100{ }^{\circ} \mathrm{C}$ in air.

POOH Determination by Modulated DSC. Finally, the $\mathrm{POOH}$ concentration was determined by MDSC. This method is based on the measurement of the decomposition enthalpy of hydroperoxides in a neutral atmosphere, typically between $130{ }^{\circ} \mathrm{C}$ and $200{ }^{\circ} \mathrm{C}$. In this temperature range, $\mathrm{POOH}$ decomposition is mainly bimolecular. ${ }^{17,18}$ The resulting alkoxy and peroxy radicals rearrange into alkyl radicals, which then recombine by coupling or disproportionation. Thus, the simplified mechanistic scheme of $\mathrm{POOH}$ decomposition can be written such as:

(Ia) Decompostion : $2 \mathrm{POOH} \rightarrow \mathrm{PO}^{\circ}+\mathrm{PO}_{2}{ }^{\circ}+\mathrm{H}_{2} \mathrm{O}\left(\Delta H_{1}\right)$

(IIa) $\beta$ scission : $\mathrm{PO}^{\circ} \rightarrow \mathrm{P}^{\mathrm{H}}=\mathrm{O}+\mathrm{P}^{\circ}\left(\Delta H_{2 a}\right)$

(IIb) $\mathrm{H}$ abstraction $: \mathrm{PO}^{\circ}+\mathrm{PH} \rightarrow \mathrm{P}-\mathrm{OH}+\mathrm{P}^{\circ}\left(\Delta H_{2 b}\right)$

(III) $\mathrm{H}$ abstraction $: \mathrm{PO}_{2}{ }^{\circ}+\mathrm{PH} \rightarrow \mathrm{POOH}+\mathrm{P}^{\circ}\left(\Delta H_{3}\right)$

(IVa) Coupling : $\mathrm{P}^{\circ}+\mathrm{P}^{\circ} \rightarrow \mathrm{P}-\mathrm{P}\left(\Delta H_{4 a}\right)$

(IVb) Disproportionation : $\mathrm{P}^{\circ}+\mathrm{P}^{\circ} \rightarrow \mathrm{PH}+\mathrm{F}\left(\Delta H_{4 b}\right)$

where $\mathrm{F}$ accounts for a vinylidene double bond and $\Delta H_{i}$ are the elementary enthalpies of the chemical events under consideration.

The corresponding total decomposition enthalpy (expressed in $\mathrm{kJ} /$ mol of $\mathrm{POOH}$ ) is the algebraic sum of all elementary enthalpies:

$$
\begin{aligned}
\Delta H_{\text {theory }} & =\Delta H_{1}+\alpha_{2} \Delta H_{2 a}+\left(1-\alpha_{2}\right) \Delta H_{2 b}+\Delta H_{3}+\alpha_{4} \Delta H_{4 a} \\
& +\left(1-\alpha_{4}\right) \Delta H_{4 b}
\end{aligned}
$$

where $\alpha_{2}$ and $\left(1-\alpha_{2}\right)$ are the respective partition coefficients between reaction paths (IIa) and (IIb), and $\alpha_{4}$ and $\left(1-\alpha_{4}\right)$ are those between reaction paths (IVa) and (IVb). In the case of PE, but also of copolymers and terpolymers based on the ethylene monomer (e.g., EPR and EPDM), typical values for these coefficients are: $\alpha_{2}=0.7$ and $\alpha_{4}=0.5^{10,48}$

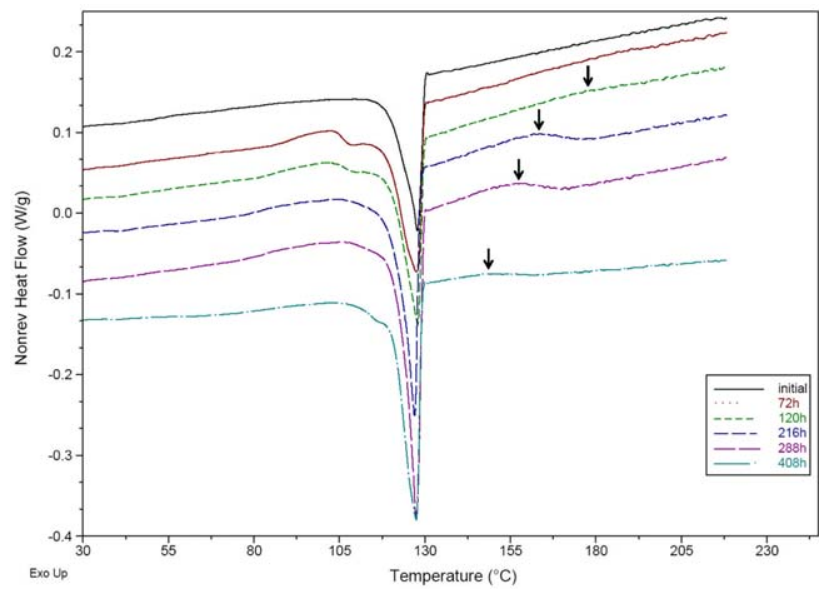

Figure 4. Examples of non-reversible MDSC thermograms of virgin and thermo-oxidized PE films. Thermal ageing conditions: $100{ }^{\circ} \mathrm{C}$ in air for $408 \mathrm{~h}$. The arrows indicate the maxima of the decomposition exotherm of $\mathrm{POOH}$. [Color figure can be viewed in the online issue, which is available at wileyonlinelibrary.com.]

Values of $\Delta H_{i}$ were calculated from the classical concepts of thermochemistry, that is, as a function of the dissociation energies of the different chemical bonds broken or formed in each chemical event. Their calculation is detailed in Appendix A. It comes finally: $\Delta H_{\text {theory }}=-291 \mathrm{~kJ} / \mathrm{mol}$.

Samples of about $5 \mathrm{mg}$ were heated under a nitrogen flow of $50 \mathrm{~mL} / \mathrm{min}$ from $20{ }^{\circ} \mathrm{C}$ to $220{ }^{\circ} \mathrm{C}$ with a heating rate of $1{ }^{\circ} \mathrm{C} /$ min and a superimposed temperature modulation (of amplitude $=0.159{ }^{\circ} \mathrm{C}$ and period $=60 \mathrm{~s}$ ) in the cavity of a TA Instruments Q1000 calorimeter. The decomposition enthalpy of hydroperoxides $\Delta H_{\mathrm{POOH}}$ was graphically determined in the non-reversible MDSC signal as the area under the exotherm located in the $150{ }^{\circ} \mathrm{C}-200{ }^{\circ} \mathrm{C}$ range, that is, just above the contribution of the melting endotherm centered around $128^{\circ} \mathrm{C}$.

Examples of non-reversible MDSC thermograms of virgin and thermo-oxidized PE films are presented in Figure 4. The top of the decomposition exotherm is indicated by an arrow. One observes clearly an increase then a decrease in the area of this peak with the exposure time in air at $100{ }^{\circ} \mathrm{C}$.

The POOH concentration was then deduced with the following equation:

$$
[\mathrm{POOH}]=\frac{\Delta H_{\mathrm{POOH}}}{\Delta H_{\text {theory }}}
$$

Carbonyl Titration by FTIR- $\mathrm{NH}_{3}$. Virgin and thermooxidized PE films were exposed in a closed glass vessel at room temperature in an atmosphere fully saturated in ammonia for converting all carboxylic acids and esters, respectively, into ammonium carboxylates and primary amides according to the following reactions: ${ }^{49,50}$

$$
\begin{gathered}
\mathrm{P}^{=\mathrm{O}}-\mathrm{OH}+\mathrm{NH}_{3} \rightarrow \mathrm{P}^{=\mathrm{O}}-\mathrm{O}^{-}+\mathrm{NH}_{4}{ }^{+} \\
\mathrm{P}^{=\mathrm{O}}-\mathrm{O}-\mathrm{P}+\mathrm{NH}_{3} \rightarrow \mathrm{P}^{=}-\mathrm{OH}_{2}+\mathrm{P}-\mathrm{OH}
\end{gathered}
$$

Gaseous $\mathrm{NH}_{3}$ was generated from a pure $\mathrm{NH}_{3}$ solution deposited at the bottom of the vessel maintained under vacuum (i.e., 


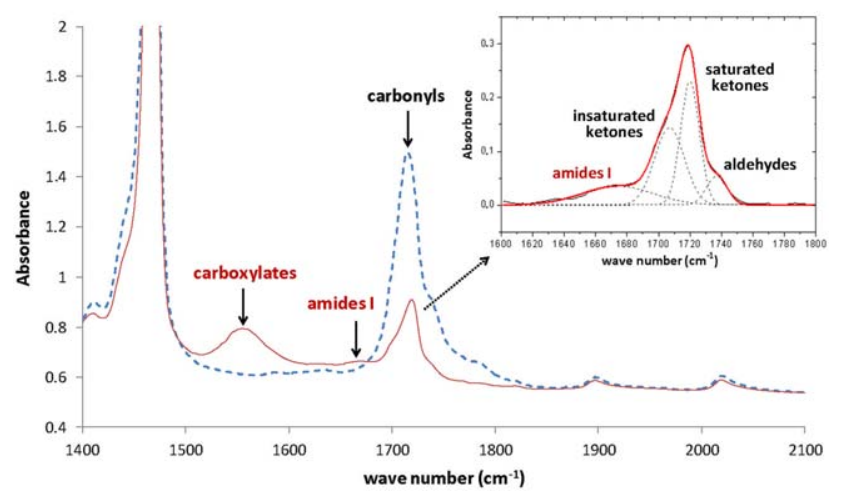

Figure 5. Example of IR spectra of thermo-oxidized PE films before (dash lines) and after (solid lines) $\mathrm{NH}_{3}$ treatment. Thermal ageing conditions: $100{ }^{\circ} \mathrm{C}$ in air for $216 \mathrm{~h}$. The inset shows the deconvolution of the composite absorption band relative to carbonyl groups not having reacted with $\mathrm{NH}_{3}$. [Color figure can be viewed in the online issue, which is available at wileyonlinelibrary.com.]

$10^{-3}$ bars) for $10 \mathrm{~min}$. After a period of 1 week, when reactions (6) and (7) were completed, ${ }^{51}$ the films were analyzed by FTIR spectrophotometry.

Examples of IR spectra of thermo-oxidized PE films after and before $\mathrm{NH}_{3}$ treatment are presented in Figure 5. As expected, $\mathrm{NH}_{3}$ treatment leads to a significant reduction of the absorbance of the carbonyl region (typically between 1690 and $1760 \mathrm{~cm}^{-1}$ ) and the formation of two new absorption bands characteristic to ammonium carboxylates and primary amides, respectively, centered around 1555 and $1680 \mathrm{~cm}^{-1}$. The concentrations of carboxylic acids and esters were calculated with the Beer-Lambert's law from the absorbances at 1555 and $1680 \mathrm{~cm}^{-1}$ and taking values of molar extinction coefficient of 330 and $405 \mathrm{~L} / \mathrm{mol} / \mathrm{cm}$, respectively. ${ }^{26,50,52}$

An example of mathematical deconvolution (with Origin 8 commercial software) of the composite absorption band relative to carbonyl groups not having reacted with $\mathrm{NH}_{3}$ is shown in the inset of Figure 5. It appears clearly that this remaining band is composed of three elementary contributions attributed to unsaturated and saturated ketones (at 1705 and $1719 \mathrm{~cm}^{-1}$, respectively) and aldehydes (at $1736 \mathrm{~cm}^{-1}$ ). The total concentrations of ketones and aldehydes were calculated with the Beer-Lambert's law from the absorbances at 1705, 1719, and $1680 \mathrm{~cm}^{-1}$ and taking values of molar extinction coefficient of 300, 300, and $155 \mathrm{~L} / \mathrm{mol} / \mathrm{cm}$, respectively. ${ }^{27}$

An example of subtraction in the carbonyl region of the IR spectra obtained before and after $\mathrm{NH}_{3}$ treatment is reported in Figure 6. The mathematical deconvolution (with Origin 8 commercial software) of the resulting composite absorption band allowed highlighting the elementary contributions of the two types of carbonyl groups having reacted with $\mathrm{NH}_{3}$, that is, carboxylic acids (at 1700 and $1713 \mathrm{~cm}^{-1}$ ) and esters (at $1738 \mathrm{~cm}^{-1}$ ). These contributions allowed confirming the concentration values of carboxylic acids and esters determined previously from the absorption bands of their reaction products with $\mathrm{NH}_{3}$. The total concentrations of carboxylic acids and esters were calculated with the Beer-Lambert's law from the absorbances at 1700,1713 , and $1738 \mathrm{~cm}^{-1}$ and by taking values of molar extinction coefficient of 680,680 , and $590 \mathrm{~L} / \mathrm{mol} / \mathrm{cm}$, respectively. ${ }^{27,53}$

To summarize, FTIR- $\mathrm{NH}_{3}$ allowed detecting and titrating four main types of carbonyl groups during the course of PE thermal oxidation: ketones, carboxylic acids, aldehydes, and esters. To demonstrate that it is a quite reliable analytical method, the summation of the elementary concentrations of these carbonyl groups was compared with their total concentration determined with the Beer-Lambert's law from the absorbance at $1718 \mathrm{~cm}^{-1}$ before $\mathrm{NH}_{3}$ treatment. To satisfy this equality, it was necessary to take a value of $335 \mathrm{~L} / \mathrm{mol} / \mathrm{cm}$ for the composite molar extinction coefficient which, according to literature, ${ }^{5}$ is quite realistic.

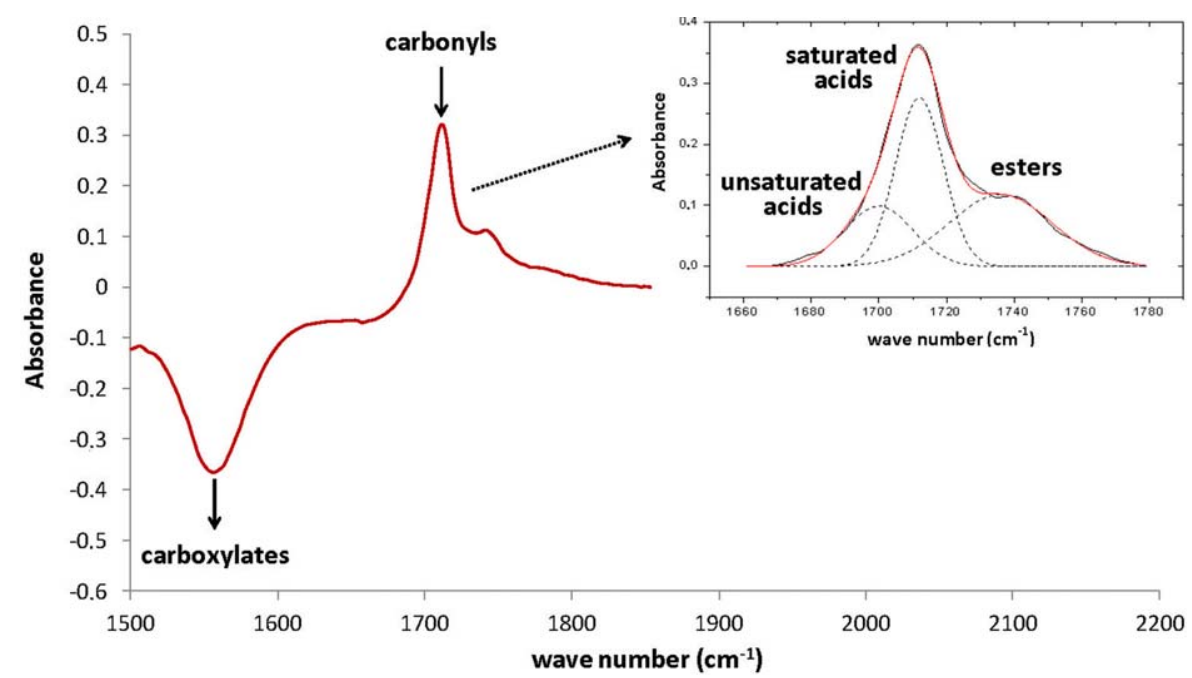

Figure 6. Example of subtraction in the carbonyl region of the IR spectra obtained before and after $\mathrm{NH}_{3}$ treatment (see Figure 5). Thermal ageing conditions: $100{ }^{\circ} \mathrm{C}$ in air for $216 \mathrm{~h}$. The inset shows the deconvolution of the remaining composite absorption band relative to carbonyl groups having reacted with $\mathrm{NH}_{3}$. [Color figure can be viewed in the online issue, which is available at wileyonlinelibrary.com.] 

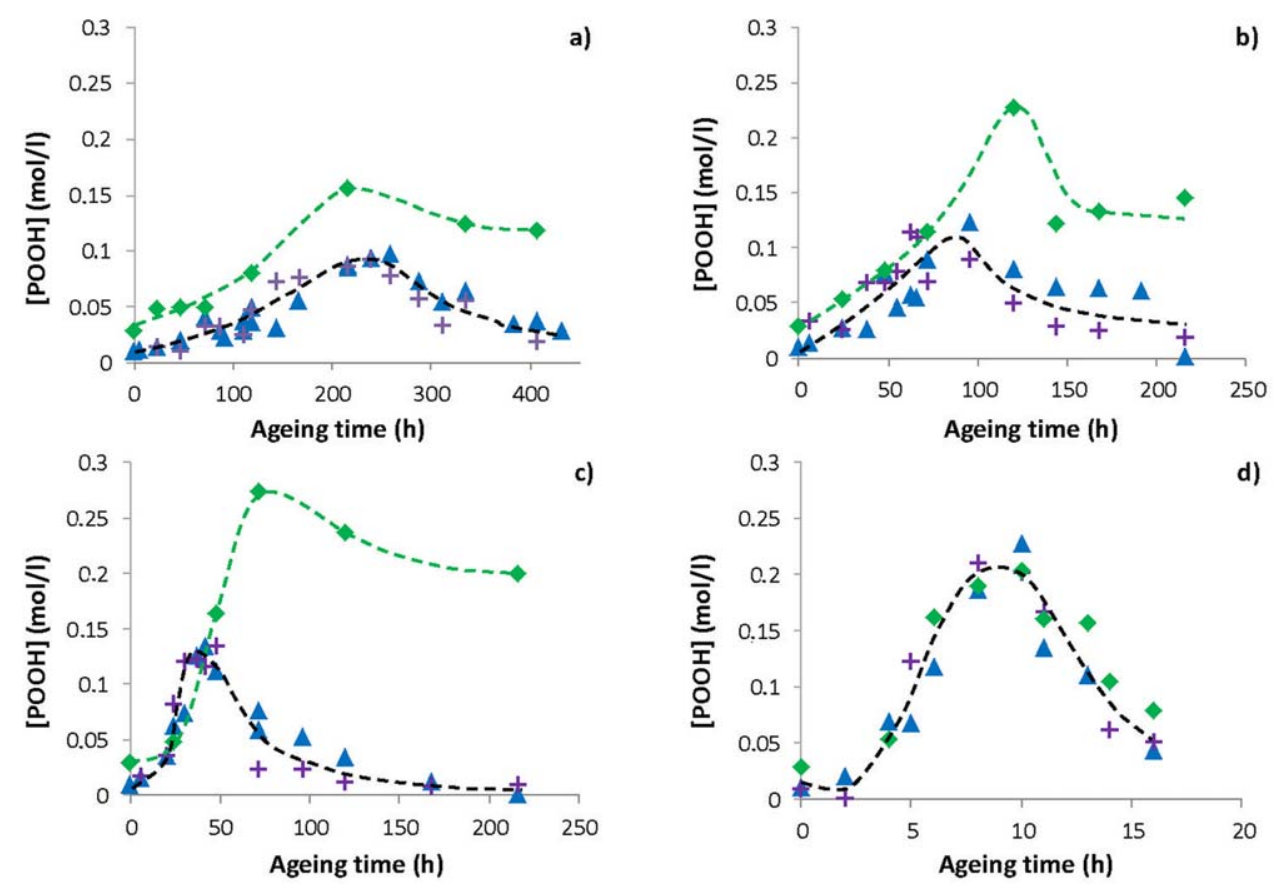

Figure 7. Changes in $\mathrm{POOH}$ concentration during the thermal ageing of $\mathrm{PE}$ films in air at $100{ }^{\circ} \mathrm{C}(\mathbf{a}), 110{ }^{\circ} \mathrm{C}(\mathbf{b}), 120{ }^{\circ} \mathrm{C}(\mathbf{c})$, and $140{ }^{\circ} \mathrm{C}(\mathbf{d})$. Comparison of the results obtained by three different titration methods: $\mathrm{SO}_{2}$-FTIR $(\boldsymbol{\Delta})$, iodometry $(\bullet)$, and $\operatorname{MDSC}(+)$. [Color figure can be viewed in the online issue, which is available at wileyonlinelibrary.com.]

Measurement of Molecular Masses by HT-GPC. The consequences of the thermal oxidation on the macromolecular structure of PE were determined at $140{ }^{\circ} \mathrm{C}$ by HT-GPC. Experiments were carried out with a PL-GPC 220 Agilent Technologies device equipped with a guard column, two columns branded PlGel Olexis connected in series, and three different (refractive index, viscometer, and light scattering) detectors acting in concert and providing distinct but complementary information. This advanced technology allows a direct measurement of the molecular masses (without extrapolation, correction, or column calibration) and degree of branching in a single experiment. The eluent was 1,2,4-trichlorobenzene (TCB) stabilized by 0.025 wt $\%$ of 2,6-di-tert-butyl-4-methylphenol (BHT). It was filtered with a $1 \mu \mathrm{m}$ pore size membrane (in glass fibers) before use. The injection volume was $100 \mu \mathrm{L}$ and the flow rate was $1 \mathrm{~mL} /$ min. PE samples were dissolved in BHT/TCB (at a concentration of $2 \mathrm{~g} / \mathrm{L}$ ) at $140{ }^{\circ} \mathrm{C}$ under stirring for $1 \mathrm{~h}$.

\section{RESULTS AND DISCUSSION}

First of all, the course of the PE thermal oxidation was monitored at molecular scale.

\section{Molecular Scale}

Changes in $\mathbf{P O O H}$ Concentration. Figure 7 displays the changes in $\mathrm{POOH}$ concentration versus exposure time in air between $100{ }^{\circ} \mathrm{C}$ and $140{ }^{\circ} \mathrm{C}$ determined by the three analytical methods under study (i.e., $\mathrm{SO}_{2}$-FTIR, iodometry, and MDSC). One observes that $\mathrm{POOH}$ accumulate in PE films up to a maximum concentration $\left([\mathrm{POOH}]_{S}\right)$ characterizing a steady-state, that is, an equilibrium state between their formation in propagation and their decomposition in initiation (see thermal oxidation scheme presented in introduction). The time to reach
$[\mathrm{POOH}]_{S}$ is called "oxidation induction time" $\left(t_{i}\right)$. It appears clearly that $[\mathrm{POOH}]_{S}$ is an increasing function of temperature, whereas $t_{i}$ is a decreasing function of temperature.

However, as the substrate concentration depletes during the thermal exposure, the steady-state cannot be indefinitely maintained and thus, the $\mathrm{POOH}$ concentration ends up decreasing. It is interesting to notice that the initial value of $[\mathrm{POOH}]$ is ranged between $1 \times 10^{-2}$ and $3 \times 10^{-2} \mathrm{~mol} / \mathrm{L}$ which, according to literature, ${ }^{17}$ corresponds to a very low pre-oxidation level of PE films. Such an order of magnitude was commonly used for simulating the thermal oxidation kinetics of unstabilized and unfilled PE matrices in the literature. ${ }^{10,11,18}$

It appears clearly that $\mathrm{SO}_{2}$-FTIR and MDSC lead to very similar results. As previously said in introduction, MDSC is considered as the most relevant method for $\mathrm{POOH}$ titration by many authors. $^{33,36,37}$ To demonstrate that it titrates only $\mathrm{POOH}$, complementary MDSC experiments were performed on thermo-oxidized $\mathrm{PE}$ films after $\mathrm{SO}_{2}$ treatment, that is, after total conversion of $\mathrm{POOH}$ into hydrosulfates. As expected, the resulting $\mathrm{POOH}$ concentrations are very low: they are typically ranged between $3 \times$ $10^{-3}$ and $3 \times 10^{-2} \mathrm{~mol} / \mathrm{L}$ (Figure 8). This upper boundary is of the order of magnitude of the initial $\mathrm{POOH}$ concentration of $\mathrm{PE}$ films (i.e., $10^{-2} \mathrm{~mol} / \mathrm{L}$ ), which roughly corresponds to the detection threshold of the two spectrochemical techniques under study (i.e., iodometry and $\mathrm{SO}_{2}$-FTIR). Because of its greater sensitivity, MDSC was chosen as the reference titration method in this study.

In contrast, the fact that $\mathrm{SO}_{2}$-FTIR gives access to the same $\mathrm{POOH}$ concentrations than MDSC is quite surprising given the numerous potential sources of error reported for this method in 

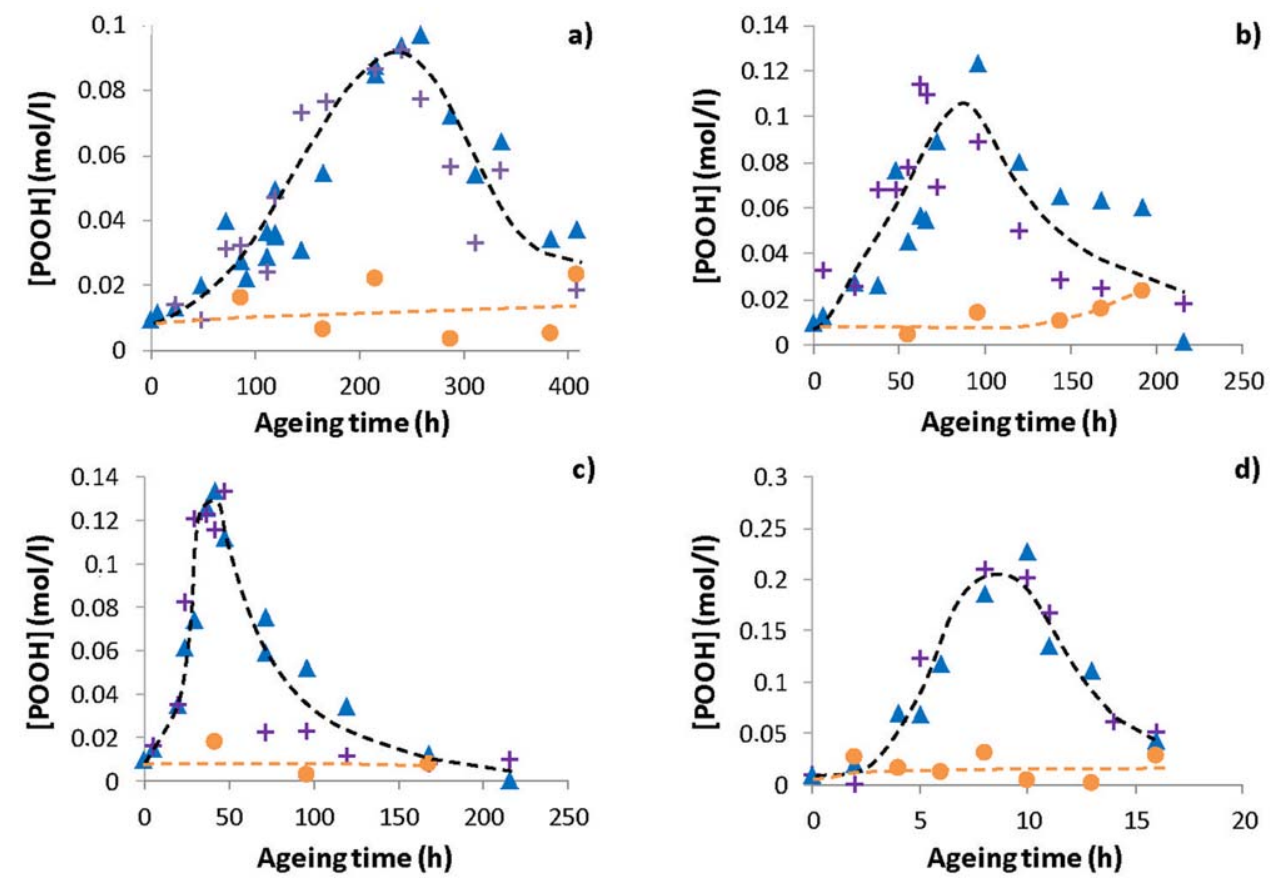

Figure 8. Changes in POOH concentration determined by MDSC before (+) and after $(\bullet) \mathrm{SO}_{2}$ treatment of thermo-oxidized PE films. Thermal ageing conditions: $100^{\circ} \mathrm{C}(\mathrm{a}), 110^{\circ} \mathrm{C}(\mathrm{b}), 120^{\circ} \mathrm{C}(\mathrm{c})$, and $140{ }^{\circ} \mathrm{C}$ (d) in air. [Color figure can be viewed in the online issue, which is available at wileyonlinelibrary.com.]

the literature. ${ }^{25,28,54}$ It can be concluded that: (i) The experimental protocol developed in this study, but also the way to exploit results, are rigorous; (ii) Hydrosulfates are relatively stable at ambient temperature contrarily to the previous findings of Jacobson. ${ }^{25}$

Finally, a kinetic analysis was performed to confirm definitively the reliability of both titration methods. In particular, it was tried to demonstrate the correctness of the values of $[\mathrm{POOH}]_{S}$ and $\left(t_{i}\right)$. Since $\mathrm{POOH}$ decomposition is mainly bimolecular in the temperature range under investigation, it was possible to derive the analytical expressions of both quantities from the thermal oxidation mechanistic scheme presented in introduction ${ }^{17,18}$ :

$$
[\mathrm{POOH}]_{S}=\frac{k_{3}[\mathrm{PH}]_{0}}{2 \sqrt{k_{1 b} k_{6}}} \text { and } t_{i}=\frac{1-\ln Y_{0}}{k_{3}[\mathrm{PH}]_{0} \sqrt{\frac{k_{1 b}}{k_{6}}}}
$$

where $k_{1 \mathrm{~b}}, k_{3}$, and $k_{6}$ are the respective rate constants of initiation, propagation, and apparent termination steps. Their respective Arrhenius laws have been determined in a previous

Table I. Arrhenius Parameters of Some Rate Constants of PE Thermal Oxidation

\begin{tabular}{lll}
\hline $\begin{array}{l}\text { Rate constant } \\
(\mathrm{L} / \mathrm{mol} / \mathrm{s})\end{array}$ & $\begin{array}{l}\text { Pre-exponential factor } \\
(\mathrm{L} / \mathrm{mol} / \mathrm{s})\end{array}$ & $\begin{array}{l}\text { Activation energy } \\
(\mathrm{kJ} / \mathrm{mol})\end{array}$ \\
\hline $\mathrm{k}_{1 \mathrm{~b}}$ & $2.8 \times 10^{9}$ & 105 \\
$\mathrm{k}_{3}$ & $1.5 \times 10^{10}$ & 73 \\
$\mathrm{k}_{6}$ & $3.0 \times 10^{9}$ & 0 \\
\hline
\end{tabular}

publication. ${ }^{10}$ As an information, they are recalled in Table I. $[\mathrm{PH}]_{0}$ is the initial concentration of methylene groups in the amorphous phase (i.e., $60 \mathrm{~mol} / \mathrm{L}$ ) and $Y_{0}$ is the reduced initial concentration of $\mathrm{POOH}$ :

$$
Y_{0}=\frac{[\mathrm{POOH}]_{0}}{[\mathrm{POOH}]_{S}}
$$

In a first approach, the detection threshold of the spectrochemical techniques (i.e., $3 \times 10^{-2} \mathrm{~mol} / \mathrm{L}$ ) was assigned to $[\mathrm{POOH}]_{0}$.

Theoretical values of $[\mathrm{POOH}]_{S}$ and $t_{i}$ were calculated with eq. (8). They are compared with experimental results in the Arrhenius diagrams of Figure 9. One observes a satisfying agreement between theory and experiment, which demonstrates the reliability of the $\mathrm{SO}_{2}$-FTIR and MDSC methods. It is also interesting to notice that the slopes of these straight-lines give access to the activation energies of $[\mathrm{POOH}]_{S}$ and $t_{i}$. They are of 20 and $118 \mathrm{~kJ} / \mathrm{mol}$, respectively.

Iodometry leads to the same results than $\mathrm{SO}_{2}$-FTIR and MDSC in melt state [Figure $7(\mathrm{~d})$ ]. In contrast, it overestimates strongly the $\mathrm{POOH}$ concentration after the end of the induction period in solid state [Figure $7(\mathrm{a}-\mathrm{c})]$. This concentration gap is an increasing function of temperature. It can be concluded that iodometry does not only titrate $\mathrm{POOH}$, but also other types of chemical species which accumulate at high conversion ratios of oxidation process. However, these species disappear rapidly above the melting point, that is, presumably for a significant increase in molecular mobility. Among all the degradation products formed during the thermal oxidation of the PE matrix, only double bonds are capable of reacting with iodine. ${ }^{55,56}$ According to Tutorskii et al., ${ }^{56}$ this reaction would be written such as: 


$$
-\mathrm{CH}_{2}-\mathrm{CH}=\mathrm{CH}-\mathrm{CH}_{2}-+\mathrm{I}_{2}
$$

The validity of this assumption was checked by FTIR spectrophotometry. Figure 10 displays the changes in the total concentration of double bonds (i.e., including vinylene, vinyl, and vinylidene unsaturations) versus exposure time in air between $100{ }^{\circ} \mathrm{C}$ and 140 ${ }^{\circ} \mathrm{C}$. It appears clearly that this concentration is of the same order of magnitude than the absolute value of the gap between the $\mathrm{POOH}$ concentrations previously determined by iodometry and MDSC (or $\mathrm{SO}_{2}$-FTIR), i.e., $[\mathrm{POOH}]_{\text {iodometry }}-[\mathrm{POOH}]_{\mathrm{MDSC}}$.

This assumption can be also supported by kinetic considerations. Indeed, it is well known that changes in molecular mobility affect preferentially the rate of chemical reactions involving reactive species in very low concentration in the polymer matrix. In the case of thermal oxidation, these species are $\mathrm{PO}_{2}{ }^{\circ}$ radicals. In saturated hydrocarbon polymers, these radicals propagate oxidation by hydrogen abstraction. In contrast, in polydiene elastomers, an alternative path is the fast addition of $\mathrm{PO}_{2}{ }^{\circ}$ radicals onto double bonds. ${ }^{57,58}$ For sake of simplification, this second propagation is usually neglected for PE (see thermal oxidation mechanistic scheme presented in "Introduction" section) because double bonds are formed in a too low concentration to really play a key kinetic role. Many authors considered that double bonds are mainly formed in termination steps by disproportionation of radical species. ${ }^{9}$ In the present case, it is suspected that their consumption by $\mathrm{PO}_{2}{ }^{\circ}$ peroxy radicals is facilitated by a sudden increase in molecular mobility, typically when the polymer reaches its liquid state.
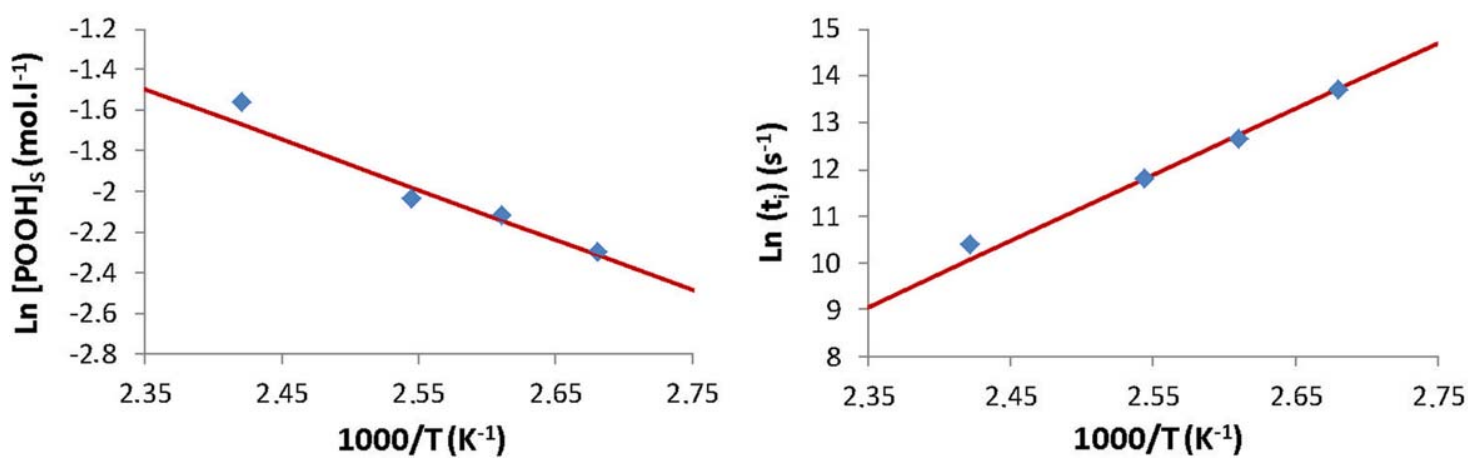

Figure 9. Arrhenius graphs of the maximal POOH concentration (left) and oxidation induction time (right) of PE films in air between $100^{\circ} \mathrm{C}$ and $140{ }^{\circ} \mathrm{C}$. Comparison between experiment (points) and theory [eq. (8), solid lines]. [Color figure can be viewed in the online issue, which is available at wileyonlinelibrary.com.]
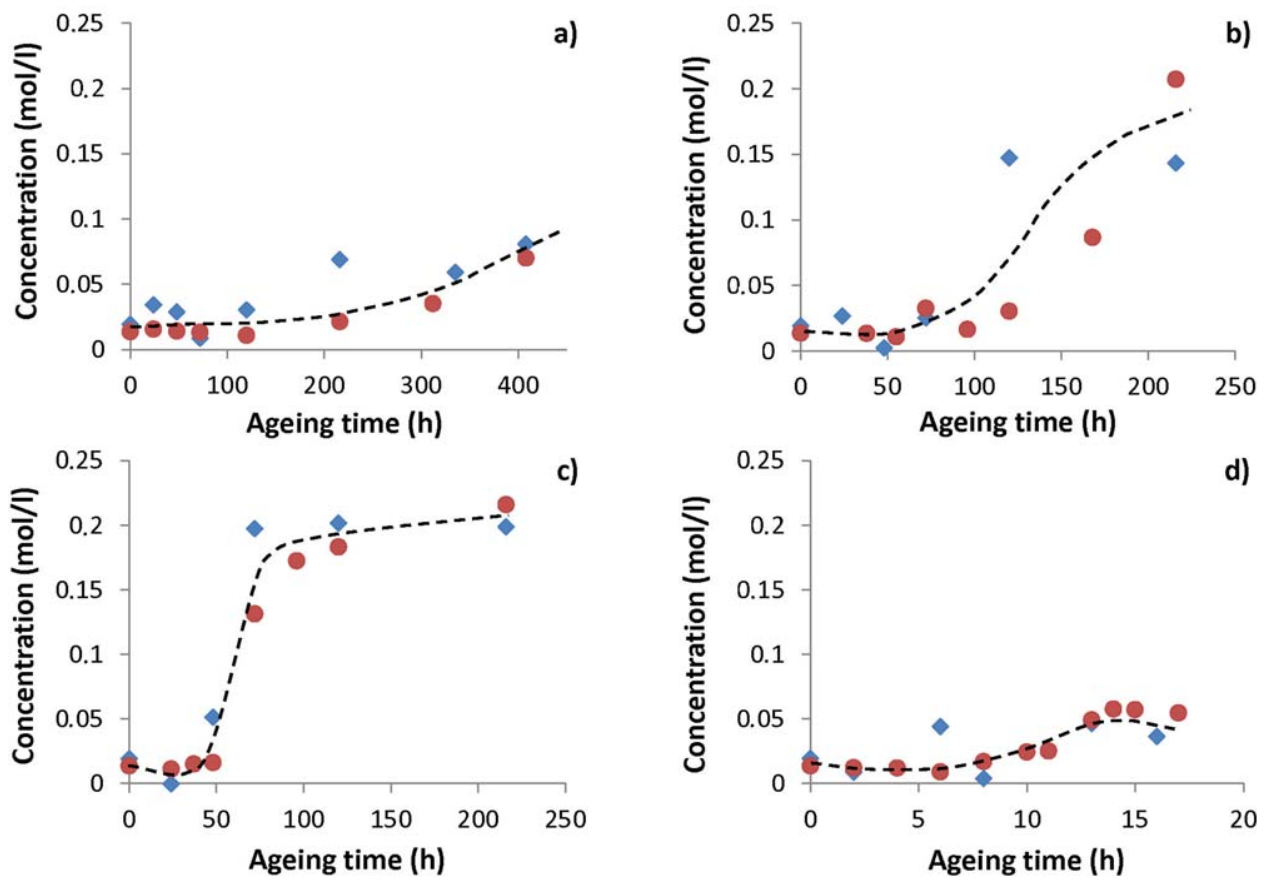

Figure 10. Changes in the total concentration of double bonds $(-)$ during the thermal ageing of PE films in air at $100{ }^{\circ} \mathrm{C}(\mathrm{a}), 110^{\circ} \mathrm{C}(\mathrm{b}), 120^{\circ} \mathrm{C}(\mathrm{c})$, and 140

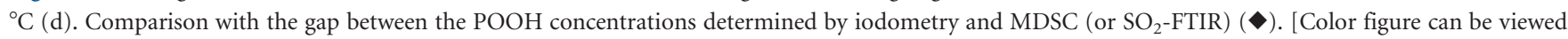
in the online issue, which is available at wileyonlinelibrary.com.] 


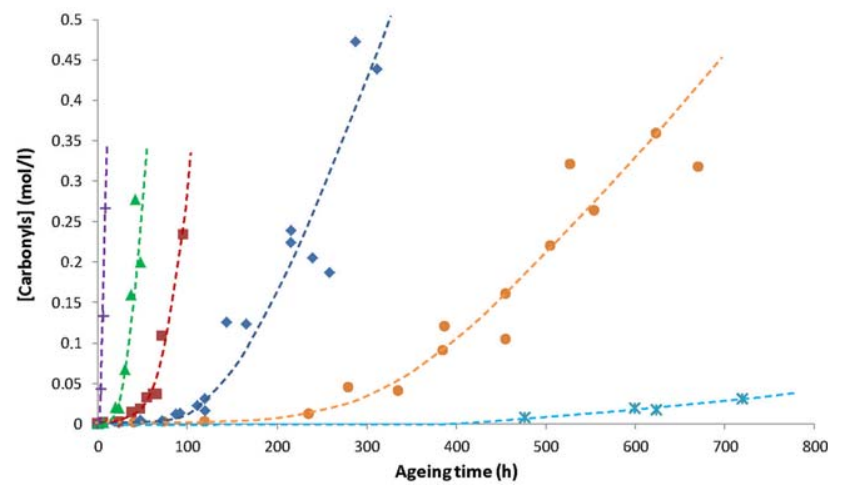

Figure 11. Changes in the total concentration of carbonyl groups during the thermal ageing of PE films in air at $80^{\circ} \mathrm{C}(\boldsymbol{*}), 90^{\circ} \mathrm{C}(\bullet), 100{ }^{\circ} \mathrm{C}(\bullet), 110^{\circ} \mathrm{C}$ $(\boldsymbol{\square}), 120^{\circ} \mathrm{C}(\boldsymbol{\Delta})$, and $140{ }^{\circ} \mathrm{C}(+)$. [Color figure can be viewed in the online issue, which is available at wileyonlinelibrary.com.]

Changes in Carbonyl Concentration. Figure 11 displays the changes in the total concentration of carbonyl products versus exposure time in air between $80{ }^{\circ} \mathrm{C}$ and $140{ }^{\circ} \mathrm{C}$ determined by FTIR analysis of the composite absorption band centered at $1718 \mathrm{~cm}^{-1}$. As already reported in previous studies ${ }^{1,10}$ and explained in introduction, one observes a sudden auto-acceleration of the oxidation reaction from the end of the induction period. Then, oxidation reaches a maximal rate characterizing a steady-state when $t \approx t_{i}$. This rate is an increasing function of temperature.

It is important to remember that four main types of carbonyl groups have been identified by $\mathrm{NH}_{3}$-FTIR in the experimental section: unsaturated and saturated ketones (at $1705 \mathrm{~cm}^{-1}$ and $1719 \mathrm{~cm}^{-1}$, respectively), carboxylic acids (at $1700 \mathrm{~cm}^{-1}$ and $1713 \mathrm{~cm}^{-1}$ ), aldehydes (at $1736 \mathrm{~cm}^{-1}$ ), and esters (at $1738 \mathrm{~cm}^{-1}$ ). Figure 12 displays their concentration changes versus exposure time in air between 100 ${ }^{\circ} \mathrm{C}$ and $140{ }^{\circ} \mathrm{C}$. As previously reported by Salvalaggio et al., ${ }^{49}$ it appears clearly that ketones are majority before all other carbonyl products. They represent about $65 \pm 10 \mathrm{~mol} \%$ of the totality of carbonyl groups whatever the exposure time and temperature, against about $15 \pm 5 \mathrm{~mol} \%$ for aldehydes and carboxylic acids, and $5 \pm 2 \mathrm{~mol} \%$ for esters. It can be thus concluded that the accumulation curves of the different carbonyl products are homothetic, that is, they result from the same oxidation kinetics. In particular, they exhibit the same induction period.

As an illustration, the concentration of ketones, determined for all the exposure times and temperatures under study, have been plotted versus the sum of the concentrations of aldehydes and carboxylic acids in Figure 13. One observes that all the points are put around a single master straight-line passing through the origin and having for slope:

$$
\frac{[\text { ketones }]}{[\text { aldehydes }]+[\text { carboxylic acids }]}=1.4
$$

It is important to recall that carbonyl products can be only formed in initiation and termination steps. However, as the rate constants of both reactions exhibit very different values of activation energy (see Table I), there is only one way to get the kind of correlation of Figure 13: each reaction must lead to the formation of all types of carbonyl groups (at least, those which predominate, that is, ketones, aldehydes, and carboxylic acids).

The case of termination was already elucidated in a previous publication, which has led to the proposal of the thermal oxidation mechanistic scheme seen in introduction. ${ }^{13,59}$ According to this scheme, aldehydes result exclusively from the $\beta$ scission of $\mathrm{PO}^{\circ}$ radicals (step VId). However, as the dissociation energy of their $\mathrm{C}-\mathrm{H}$ bond is significantly lower $(\approx 368 \mathrm{~kJ} / \mathrm{mol})$ than in methylene groups $(\approx 393 \mathrm{~kJ} /$ $\mathrm{mol}),{ }^{14}$ aldehydes are highly sensitive to radical attacks. Therefore, their rapid oxidation leads to the formation of carboxylic acids, as proposed by many authors in the literature. ${ }^{41,60}$ In first approach, one could simply reveal these latter into the thermal oxidation mechanistic scheme by replacing half of the aldehydes by carboxylic acids as already done, for instance, in the case of poly(ethylene terephthalate) (PET). ${ }^{61}$ At last, ketones are formed by disproportionation of $\mathrm{PO}^{\circ}$ radicals (event VIc).

The case of initiation is more complicated because, in the temperature range under study, the main source of radicals source is the bimolecular decomposition of $\mathrm{POOH}$ (Ib). If the formation of aldehydes and carboxylic acids can be explained with the same chemical events evoked in termination, in contrast, there is no suggestion of formation mechanism of ketones starting from two $\mathrm{POOH}$ in the literature. To tentatively overcome such a deficiency, the bimolecular decomposition of $\mathrm{POOH}$ has been modified as follows:

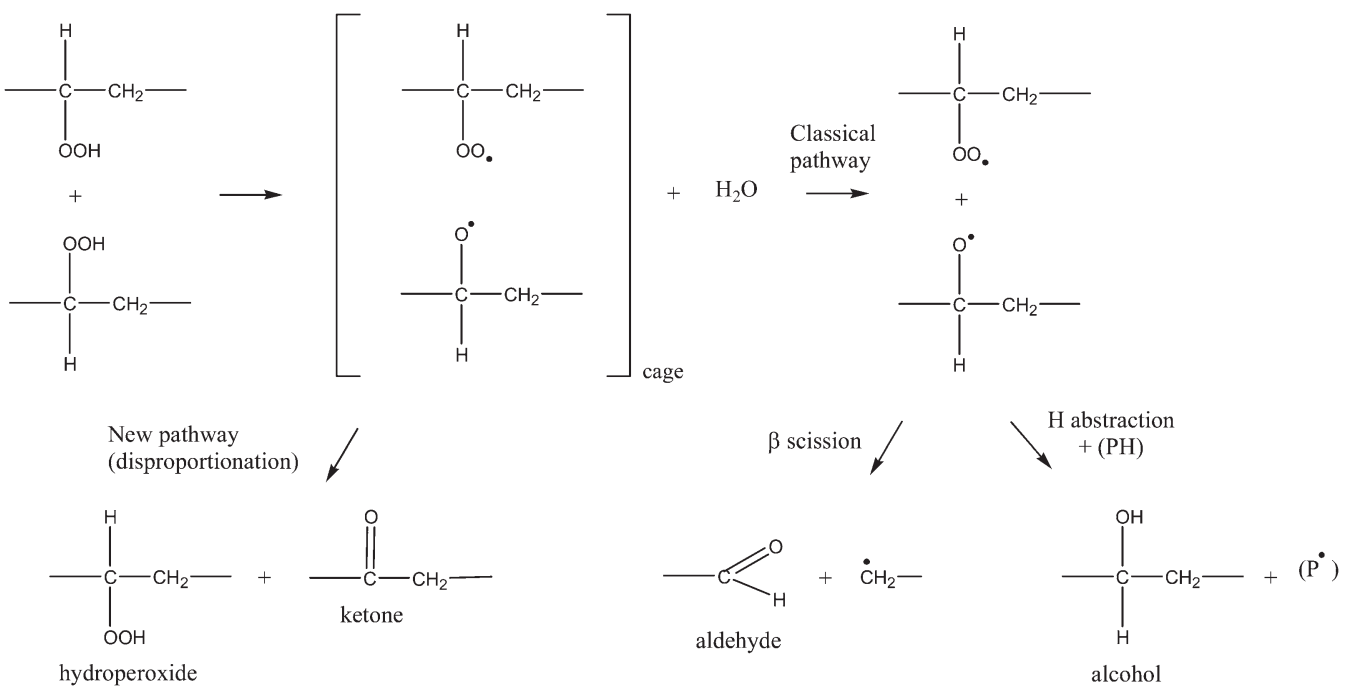



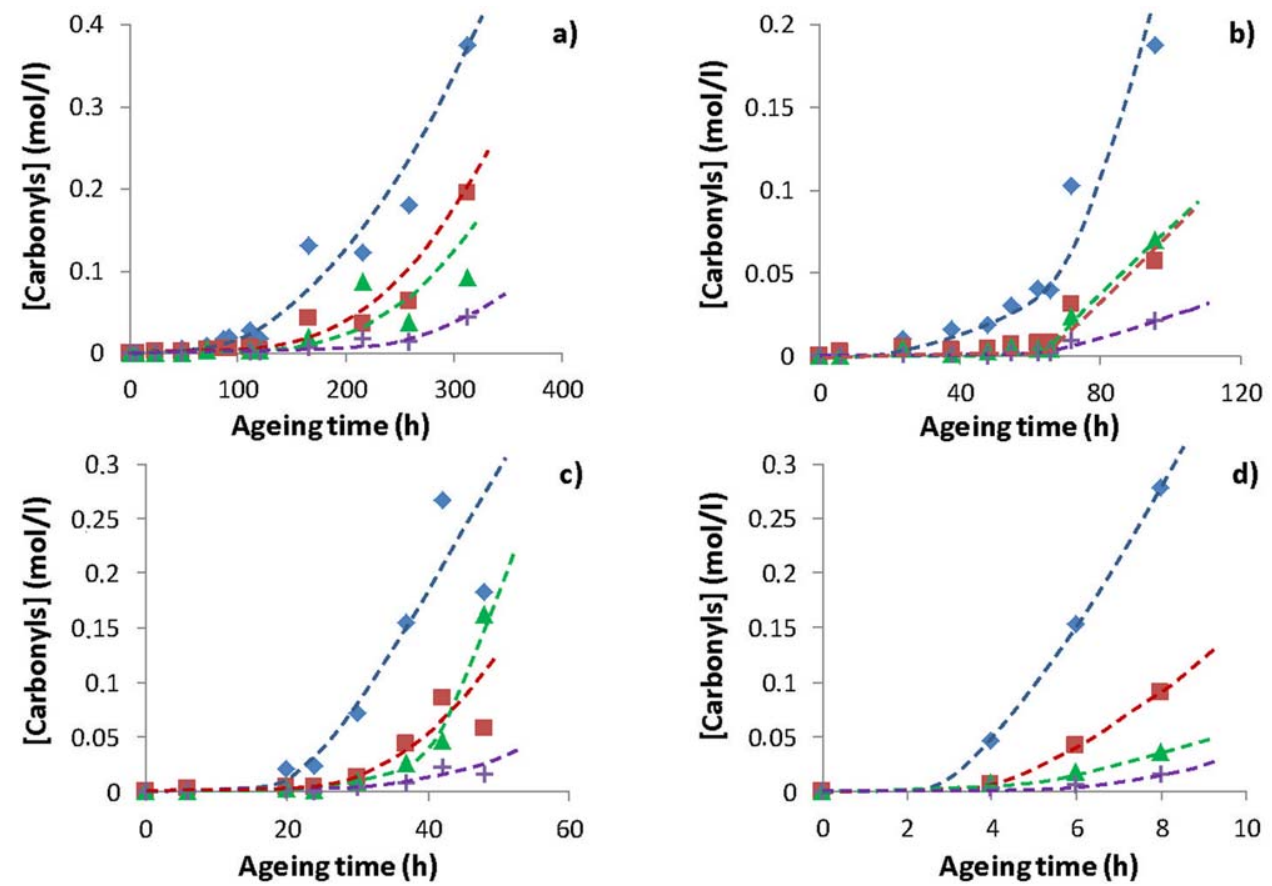

Figure 12. Changes in the concentration of ketones $(\bullet)$, aldehydes $(\boldsymbol{\square})$, carboxylic acids $(\mathbf{\Lambda})$, and esters $(+)$ during the thermal ageing of PE films in air at $100{ }^{\circ} \mathrm{C}(\mathrm{a}), 110^{\circ} \mathrm{C}(\mathrm{b}), 120^{\circ} \mathrm{C}(\mathrm{c})$, and $140{ }^{\circ} \mathrm{C}$ (d). [Color figure can be viewed in the online issue, which is available at wileyonlinelibrary.com.]

This new scheme is composed of two main competitive reaction pathways. According to the standard pathway, the bimolecular decomposition of $\mathrm{POOH}$ leads to the formation of a water molecule and radicals $\left(\mathrm{PO}_{2}{ }^{\circ}\right.$ and $\left.\mathrm{PO}^{\circ}\right)$ which diffuse rapidly outside the cage. Then, $\mathrm{PO}^{\circ}$ radicals rearrange rapidly by $\beta$ scission or hydrogen abstraction to form $\mathrm{P}^{\circ}$ radicals and a variety of oxidation products such as aldehydes (thus carboxylic acids) and alcohols. In contrast, according to the competitive pathway, $\mathrm{PO}_{2}^{\circ}$ and $\mathrm{PO}^{\circ}$ radicals remain trapped in the cage. They recombine by disproportionation leading to hydroperoxides and ketones. It is not an initiating event because it does not generate radical species. From a kinetic point of view, this mechanistic scheme should be now written such as:

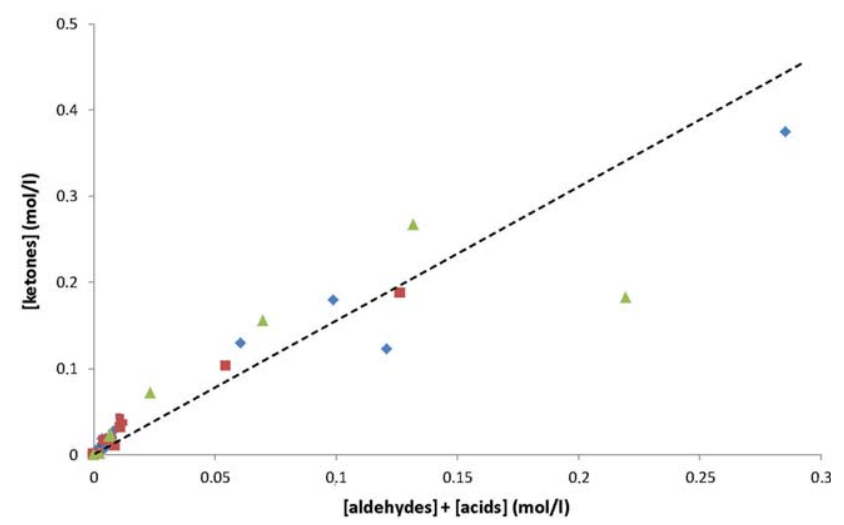

Figure 13. Concentration of ketones versus concentration sum of aldehydes and carboxylic acids of thermo-oxidized PE films in air at $80{ }^{\circ} \mathrm{C}$ (*), $90{ }^{\circ} \mathrm{C}(\bullet), 100{ }^{\circ} \mathrm{C}(\bullet), 110{ }^{\circ} \mathrm{C}(\boldsymbol{\square}), 120{ }^{\circ} \mathrm{C}(\boldsymbol{\Delta})$, and $140{ }^{\circ} \mathrm{C}(+)$. [Color figure can be viewed in the online issue, which is available at wileyonlinelibrary.com.]
Bimolecular initiation:

(Ia) $2 \mathrm{POOH} \rightarrow\left[\mathrm{PO}_{2}{ }^{\circ}{ }^{\circ} \mathrm{OP}\right]_{\text {cage }}+\mathrm{H}_{2} \mathrm{O}\left(k_{1 a}\right)$

(Ib) $\left[\mathrm{PO}_{2}^{\circ}{ }^{\circ} \mathrm{OP}\right]_{\text {cage }} \rightarrow \mathrm{PO}_{2}^{\circ}+\mathrm{P}^{\circ}+\gamma_{1} \mathrm{P}^{\mathrm{H}}=\mathrm{O}$

$+\left(1-\gamma_{1}\right) \mathrm{P}-\mathrm{OH}+\gamma_{S} \mathrm{~S}\left(k_{1 b}\right)$

(Ic) $\left[\mathrm{PO}_{2}^{\circ}{ }^{\circ} \mathrm{OP}\right]_{\text {cage }} \rightarrow \mathrm{POOH}+\mathrm{P}=\mathrm{O}\left(k_{1 c}\right)$

The next section will be dedicated to the consequences of thermal oxidation at macromolecular scale.

Macromolecular Scale. Figure 14 displays the changes in weight average molecular mass $\left(M_{w}\right)$ and PDI versus exposure time in air between $100{ }^{\circ} \mathrm{C}$ and $140{ }^{\circ} \mathrm{C}$ determined by HT-GPC. As already reported in previous studies, ${ }^{6,27,42}$ one observes that both quantities decrease catastrophically from the beginning of exposure, which suggests that an intensive chain scission process operates during the thermal oxidation of PE. As PDI tends eventually toward the asymptotic value of 2 , it can be concluded that this is a "pure" chain scission process (i.e., with absence of crosslinking). The rate of chain scissions is clearly an increasing function of temperature.

The absence of induction period confirms that HT-GPC is an analytical method more sensitive than common spectrochemical methods, in particular FTIR spectrophotometry. That is the reason why embrittlement of polyolefins is generally observed before the build-up onset of oxidation products. ${ }^{6}$ However, this scenario is less clear if one refers to the number of chain scissions.

Since one chain scission creates a new macromolecular chain and two new chain-ends, the number of chain scissions can be simply written such as: 

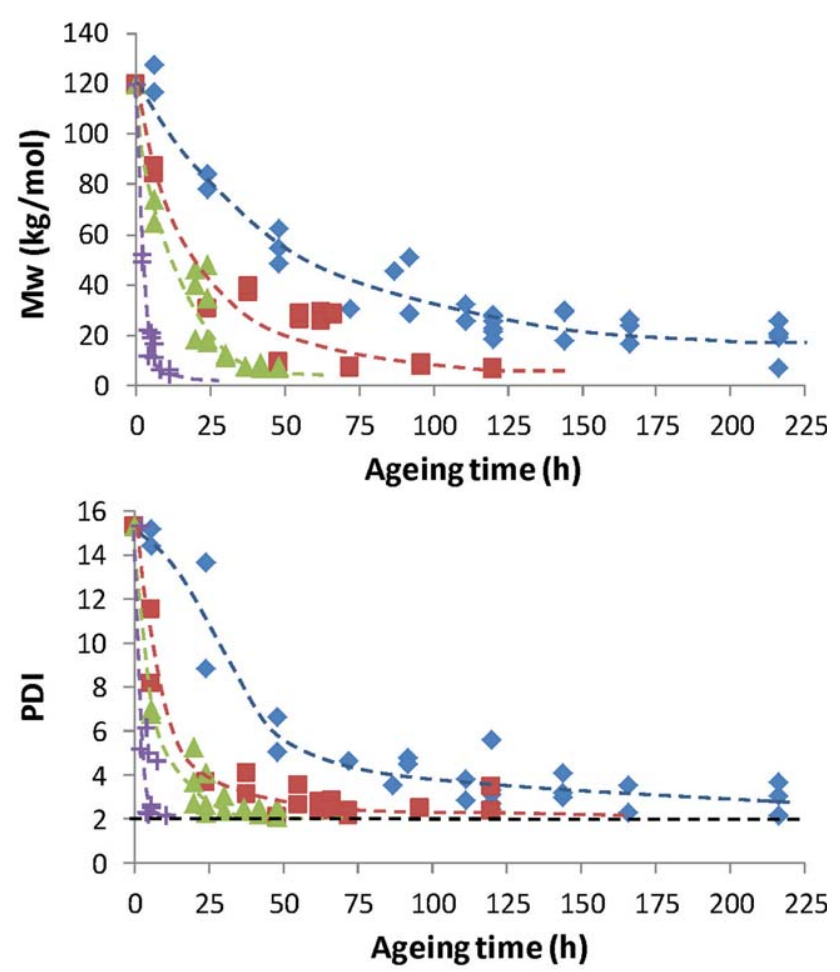

Figure 14. Changes in weight average molecular mass (top) and polydispersity index (bottom) during the thermal ageing of PE films in air at $100{ }^{\circ} \mathrm{C}$ $(\diamond), 110{ }^{\circ} \mathrm{C}(\boldsymbol{\square}), 120^{\circ} \mathrm{C}(\boldsymbol{\Delta})$, and $140{ }^{\circ} \mathrm{C}(+)$. [Color figure can be viewed in the online issue, which is available at wileyonlinelibrary.com.]

$$
S=\left(\frac{1}{M_{n}}-\frac{1}{M_{n 0}}\right) \rho_{0}
$$

Or
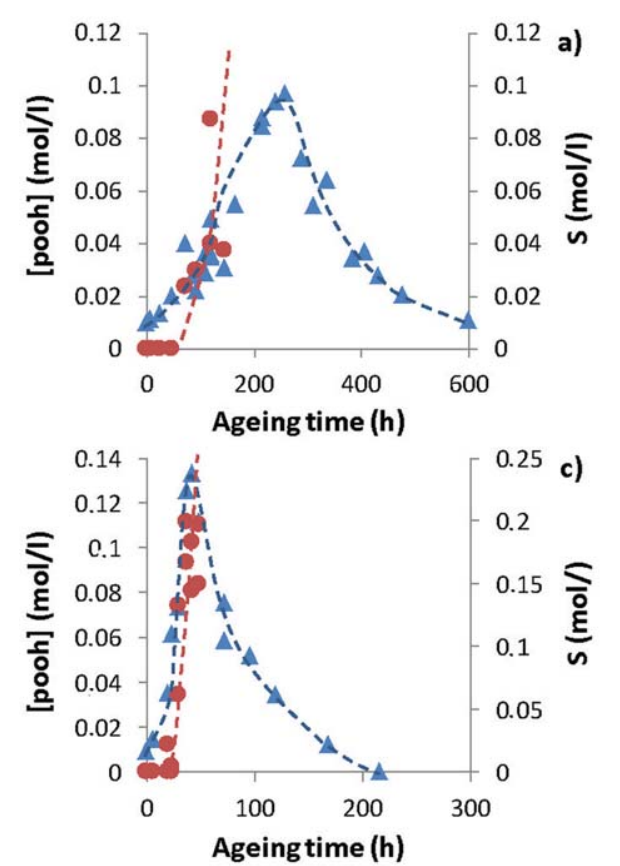

$$
S=\left(\frac{\mathrm{PDI}}{M_{w}}-\frac{\mathrm{PDI}_{0}}{M_{w 0}}\right) \rho_{0}
$$

where $\rho_{0}$ is the initial polymer density (expressed in $\mathrm{kg} / \mathrm{L}$ if $M_{n}$ and $M_{w}$ are given in $\mathrm{kg} / \mathrm{mol}$ ).

The changes in $S$ in air between $100{ }^{\circ} \mathrm{C}$ and $140{ }^{\circ} \mathrm{C}$ were calculated from eq. (12). They are compared with the corresponding changes in $[\mathrm{POOH}]$ in Figure 15. It appears clearly that chain scissions are not numerous enough to be detected by GPC for about the first half of the induction period (i.e., for $t_{i} / 2$ ). This is due to the fact that the decrease in $M_{w}$ is counterbalanced by the decrease in PDI in the early periods of exposure, thus maintaining $M_{n}$ close to its initial value $M_{n 0}$. However, when PDI approaches its asymptotic value, $M_{n}$ ends up becoming lower than $M_{n 0}$. Thenceforth, the rate of chain scissions increases suddenly up to reach a maximal value $\left(r_{S}\right)$ when $[\mathrm{POOH}] \approx$ $[\mathrm{POOH}]_{s}$. All these observations allow classifying the different analytical methods under study according to their sensitivity order:

$$
\mathrm{MDSC} \gtrsim \mathrm{SO}_{2}-\text { FTIR } \approx \text { Iodometry }>\text { GPC }>\text { standard FTIR }
$$

In the case of a bimolecular decomposition of $\mathrm{POOH}$, an analytical expression for $r_{S}$ is:

$$
r_{S}=\gamma^{\prime}{ }_{S} k_{1 b}[\mathrm{POOH}]_{S}^{2}+2 \gamma_{S}^{\prime \prime} k_{6}\left[\mathrm{PO}_{2}{ }^{\circ}\right]_{S}^{2}
$$

where $\gamma_{S}^{\prime}$ and $\gamma^{\prime \prime}{ }_{S}$ are the respective apparent yields of chain scissions in initiation and termination.

The maximal concentration of $\mathrm{PO}_{2}{ }^{\circ}$ radicals has been reported elsewhere ${ }^{17}$ :

$$
\left[\mathrm{PO}_{2}^{\circ}\right]_{S}=\frac{2 k_{1 b}[\mathrm{POOH}]_{S}^{2}}{k_{3}[\mathrm{PH}]}=\frac{k_{3}[\mathrm{PH}]}{2 k_{6}}
$$

Introducing eq. (14) into eq. (13) gives finally:

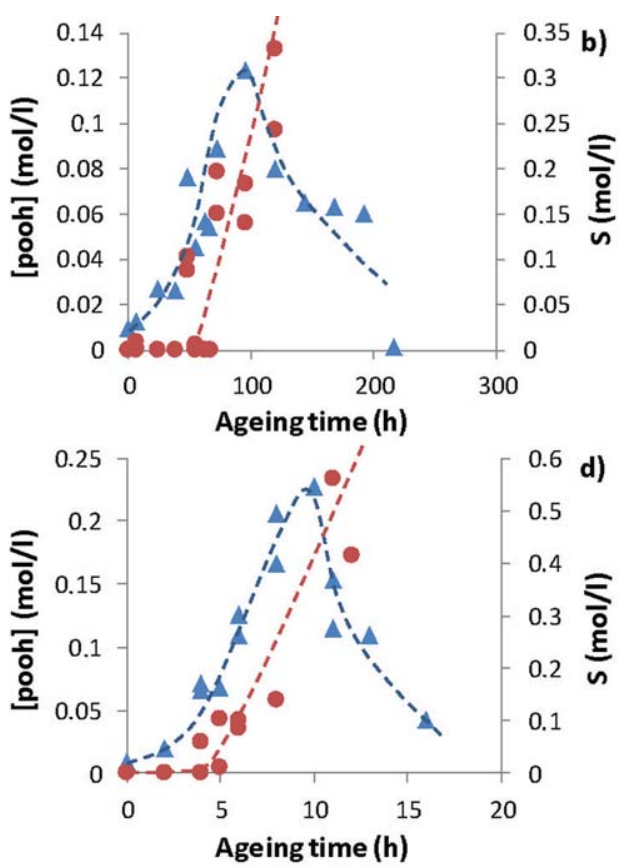

Figure 15. Changes in chain scission (-) during the thermal ageing of PE films in air at $100{ }^{\circ} \mathrm{C}(\mathrm{a}), 110{ }^{\circ} \mathrm{C}(\mathrm{b}), 120^{\circ} \mathrm{C}(\mathrm{c})$, and $140{ }^{\circ} \mathrm{C}(\mathrm{d})$. Comparison with the corresponding changes in $\mathrm{POOH}(\mathbf{\Lambda})$. [Color figure can be viewed in the online issue, which is available at wileyonlinelibrary.com.] 


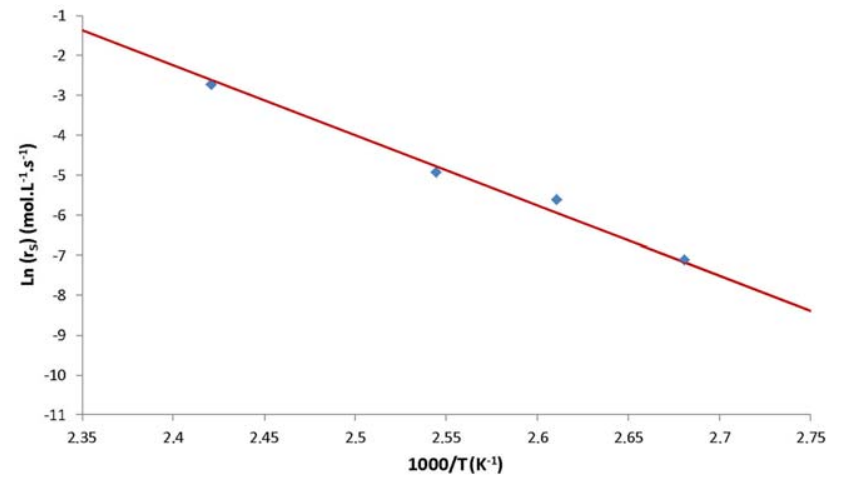

Figure 16. Arrhenius graphs of the maximal rate of chain scissions in $\mathrm{PE}$ films in air between $100{ }^{\circ} \mathrm{C}$ and $140{ }^{\circ} \mathrm{C}$. Comparison between experiment (points) and theory [eq. (15), solid lines]. [Color figure can be viewed in the online issue, which is available at wileyonlinelibrary.com.]

$$
r_{S}=\left(\gamma^{\prime}{ }_{S}+2 \gamma_{S}^{\prime \prime}\right) \frac{k_{3}^{2}[\mathrm{PH}]^{2}}{4 k_{6}}
$$

Theoretical values of $r_{S}$ were calculated with eq. (15) taking $\gamma_{\mathrm{S}}^{\prime}=\gamma^{\prime \prime}{ }_{\mathrm{S}}=0.6$ throughout the temperature range under investigation. They are compared with experimental results in the Arrhenius diagrams of Figure 16. One observes a satisfying agreement between theory and experiment, which confirms the reliability of the HT-GPC method. The activation energy of $r_{S}$ is $146 \mathrm{~kJ} / \mathrm{mol}$.

Finally, the number of chain scissions, determined for all the exposure times and temperatures under study, have been plotted versus concentration sum of aldehydes and carboxylic acids in Figure 17. One observes that all the points are gathered around a single master curve passing through the origin. This correlation allows demonstrating the validity of the assumption (made in section "Changes in carbonyl concentration") that aldehydes and their oxidation products (i.e., carboxylic acids) result exclusively from the $\beta$ scission of $\mathrm{PO}^{\circ}$ radicals.

The fact that the sum of their concentration remains lower than the number of chain scissions suggests that a non-negligible part

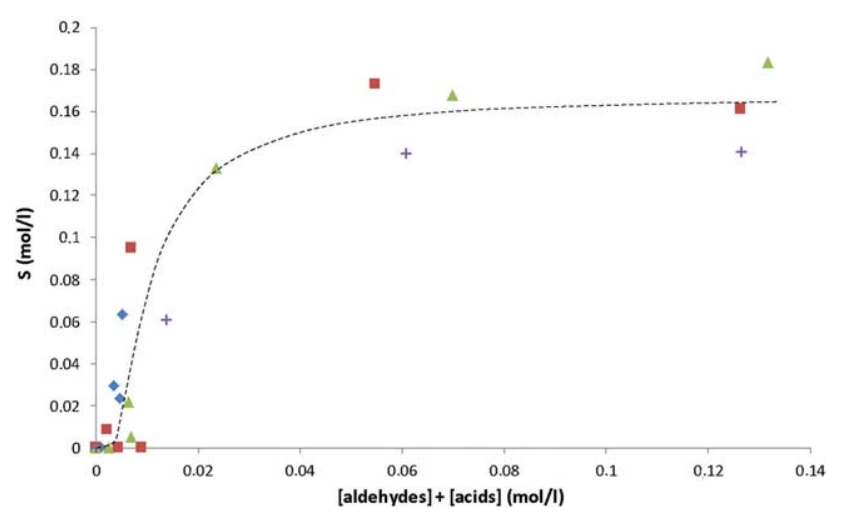

Figure 17. Concentration of chain scissions versus concentration sum of aldehydes and carboxylic acids for PE films thermo-oxidized in air at 100 ${ }^{\circ} \mathrm{C}(\bullet), 110{ }^{\circ} \mathrm{C}(\boldsymbol{\square}), 120{ }^{\circ} \mathrm{C}(\boldsymbol{\Delta})$, and $140{ }^{\circ} \mathrm{C}(+)$. [Color figure can be viewed in the online issue, which is available at wileyonlinelibrary.com.] of these carbonyl products is lost as volatile compounds during the thermal exposure. As an example, it is well known that acyl and carboxyl radicals, involved in the oxidation mechanism of aldehydes into carboxylic acids, can rearrange by $\beta$ scission to give carbon monoxide and dioxide, respectively. ${ }^{41}$ Such respective decarbonylation and decarboxylation reactions could be taken into account by lowering the values of the formation yields of carboxylic acids in initiation and termination steps.

To summarize, all these results highlight a strong correlation between the chemical processes induced by oxidation at molecular scale and their consequences at macromolecular scale.

\section{CONCLUSIONS}

The thermal oxidation of additive free PE was carefully investigated in air between $100{ }^{\circ} \mathrm{C}$ and $140{ }^{\circ} \mathrm{C}$ at both molecular and macromolecular scales with several complementary analytical methods. On one hand, the $\mathrm{POOH}$ concentration was determined by iodometry, MDSC and $\mathrm{SO}_{2}$-FTIR, whereas carbonyls products were clearly identified and titrated by $\mathrm{NH}_{3}$-FTIR. It was shown that iodometry does not only detect $\mathrm{POOH}$, but also other chemical species formed at high conversion ratios of the oxidation process, namely double bonds. On the other hand, the weight average molecular mass and polydispersity index were determined by HT-GPC for deducing the corresponding number of chain scissions. The different sensitivity levels of these techniques have been identified.

A complementary kinetic analysis was performed on key ageing criteria such as: oxidation induction time, maximal concentration of $\mathrm{POOH}$, and maximal rate of chain scissions, in order to show the efficiency of the kinetic modeling tool developed for predicting the thermal oxidation kinetics of $\mathrm{PE}$ in previous studies at the laboratory, but also for checking the correctness of experimental results.

Despite its apparent success, it appeared that this tool is unable to predict some important characteristics of the oxidation process such as: (i) The formation of a large variety of carbonyl groups (mainly ketones, aldehydes, and carboxylic acids); (ii) The existence of a correlation between the concentrations of these different carbonyl groups; (iii) The existence of a correlation between the number of chain scissions and the concentration sum of aldehydes and their oxidation products (i.e., carboxylic acids).

To tentatively overcome these deficiencies, it was proposed to improve the thermal oxidation mechanistic scheme from which the kinetic model is derived. These improvements will consist in adding: (i) An alternative reaction pathway for the bimolecular decomposition of $\mathrm{POOH}$; (ii) The rapid oxidation of aldehydes into carboxylic acids; (iii) The loss of aldehydes and carboxylic acids as volatile compounds. The validity of these different assumptions will be checked in future studies.

\section{APPENDIX}

Let us consider the following simplified mechanistic scheme for the bimolecular decomposition of hydroperoxides in a neutral atmosphere: 
Table A1. Bond Dissociation Energies ${ }^{62-64}$

\begin{tabular}{ll}
\hline Chemical bond & $\Delta \mathrm{H}(\mathrm{kJ} / \mathrm{mol})$ \\
\hline $\mathrm{O}-\mathrm{O}$ & 148 \\
$\mathrm{OO}-\mathrm{H}$ & 376 \\
$\mathrm{C}-\mathrm{O}$ & 341 \\
$\mathrm{O}-\mathrm{H}$ & 460 \\
$\mathrm{HO}-\mathrm{H}$ & 498 \\
$>\mathrm{CH}-\mathrm{H}$ & 393 \\
$>\mathrm{CH}-\mathrm{CH}_{2}-$ & 343 \\
$>\mathrm{CH}-\mathrm{CH}<$ & 328 \\
$-\mathrm{CH}=\mathrm{CH}-$ & $(2 \times) 303$ \\
\hline
\end{tabular}

(I) Decomposition : $2 \mathrm{POOH} \rightarrow \mathrm{PO}^{\circ}+\mathrm{PO}_{2}{ }^{\circ}+\mathrm{H}_{2} \mathrm{O}\left(\Delta H_{1}\right)$

(IIa) $\beta$ scission $: \mathrm{PO}^{\circ} \rightarrow \mathrm{P}^{\mathrm{H}}=\mathrm{O}+\mathrm{P}^{\circ}\left(\Delta H_{2 a}\right)$

(IIb) $\mathrm{H}$ abstraction $: \mathrm{PO}^{\circ}+\mathrm{PH} \rightarrow \mathrm{P}-\mathrm{OH}+\mathrm{P}^{\circ}\left(\Delta H_{2 b}\right)$

(III) $\mathrm{H}$ abstraction : $\mathrm{PO}_{2}^{\circ}+\mathrm{PH} \rightarrow \mathrm{POOH}+\mathrm{P}^{\circ}\left(\Delta H_{3}\right)$

(IVa) Coupling : $\mathrm{P}^{\circ}+\mathrm{P}^{\circ} \rightarrow \mathrm{P}-\mathrm{P}\left(\Delta H_{4 a}\right)$

(IVb) Disproportionation : $\mathrm{P}^{\circ}+\mathrm{P}^{\circ} \rightarrow \mathrm{PH}+\mathrm{F}\left(\Delta H_{4 b}\right)$

A rapid review of available data from organic chemistry allowed us compiling the dissociation energies of the different chemical bonds involved in this mechanistic scheme (Table A1).

The elementary enthalpies $\Delta H_{i}$ of each chemical event were calculated from the classical concepts of thermochemistry as shown below. First of all, the decomposition of one $\mathrm{POOH}$ group (I) leads to the breaking of one $\mathrm{O}-\mathrm{O}$ bond and one $\mathrm{OO}-\mathrm{H}$ bond, and the formation of one $\mathrm{HO}-\mathrm{H}$ bond, so that:

$$
\Delta H_{1}=\Delta H_{\mathrm{O}-\mathrm{O}}+\Delta H_{\mathrm{OO}-\mathrm{H}}+\Delta H_{\mathrm{HO}-\mathrm{H}}=148+376-498=26 \mathrm{~kJ} / \mathrm{mol}
$$

Then, the $\beta$ scission of one alkoxy radical (IIa) leads to the breaking of one $>\mathrm{CH}-\mathrm{CH}_{2}-$ bond and the formation of one $\mathrm{C}-\mathrm{O}$ bond, so that:

$$
\Delta H_{2 a}=\Delta H_{>\mathrm{CH}-\mathrm{CH} 2-}-\Delta H_{\mathrm{C}-\mathrm{O}}=343-341=2 \mathrm{~kJ} / \mathrm{mol}
$$

Moreover, the hydrogen abstraction by one radical (IIb and III) leads to the breaking of one $\mathrm{CH}-\mathrm{H}$ bond and the formation of one $\mathrm{O}-\mathrm{H}$ bond. This latter belongs to an alcohol in the case of an alkoxy radical, and a hydroperoxide in the case of a peroxy radical, so that:

$$
\begin{aligned}
& \Delta H_{2 b}=\Delta H_{>\mathrm{CH}-\mathrm{H}}-\Delta H_{\mathrm{O}-\mathrm{H}}=393-460=-67 \mathrm{~kJ} / \mathrm{mol} \\
& \Delta H_{3}=\Delta H_{>\mathrm{CH}-\mathrm{H}}-\Delta H_{\mathrm{OO}-\mathrm{H}}=393-376=-17 \mathrm{~kJ} / \mathrm{mol}
\end{aligned}
$$

At last, the coupling of two alkyl radicals (IVa) leads to the formation of one $\mathrm{CH}-\mathrm{CH}$ bond, so that:

$$
\Delta H_{4 a}=-\Delta H_{>\mathrm{CH}-\mathrm{CH}<}=-328 \mathrm{~kJ} / \mathrm{mol}
$$

In contrast, the disproportionation of two alkyl radicals (IVb) leads to the formation of one $\mathrm{CH}=\mathrm{CH}$ bond, so that:

$$
\Delta H_{4 b}=\Delta H_{-\mathrm{CH}=\mathrm{CH}-}=-303 \mathrm{~kJ} / \mathrm{mol}
$$

It is important to recall now that the total decomposition enthalpy of hydroperoxides (expressed in $\mathrm{kJ} / \mathrm{mol}$ of $\mathrm{POOH}$ ) writes:

$$
\begin{aligned}
& \begin{aligned}
\Delta H_{\text {theory }} & =\Delta H_{1}+\alpha_{2} \Delta H_{2 a}+\left(1-\alpha_{2}\right) \Delta H_{2 b}+\Delta H_{3}+\alpha_{4} \Delta H_{4 a} \\
& +\left(1-\alpha_{4}\right) \Delta H_{4 b}
\end{aligned} \\
& \text { with } \alpha_{2}=0.7 \text { and } \alpha_{4}=0.5 .
\end{aligned}
$$

The numerical application leads finally to:

$$
\Delta H_{\text {theory }}=-291.2 \mathrm{~kJ} / \mathrm{mol} \text {. }
$$

\section{REFERENCES}

1. Verdu, J. In Vieillissement des Plastiques; Afnor Technique; Eyrolles: Paris, 1984.

2. Singh, B.; Sharma, N. Polym. Degrad. Stab. 2008, 93, 561.

3. Habicher, W.; Bauer, I.; Pospisil, J. Macromol. Symp. 2005, 225, 147.

4. Moller, K.; Gevert, T.; Holmstrom, A. Polym. Degrad. Stab. 2001, 73, 69.

5. Mkacher, I. Vieillissement Thermique des gaines PE et PVC de Câbles Electriques, Ph.D. thesis, Arts et Métiers ParisTech, Paris, France, Oct 2012.

6. Fayolle, B.; Richaud, E.; Verdu, J.; Farcas, F. J. Mater. Sci. 2008, 43, 1026.

7. Kennedy, M. A.; Peacock, A. J.; Mandelkern, L. Macromolecules 1994, 27, 5297.

8. Risch, B. G.; Fox, S.; Van Delden, R. A. In Proceedings of the 59th International Wire \& Cable Symposium, Rhode Island, Nov 7-10, 2010.

9. Khelidj, N.; Colin, X.; Audouin, L.; Verdu, J.; MonchyLeroy, C.; Prunier, V. Polym. Degrad. Stab. 2006, 91, 1593.

10. Khelidj, N.; Colin, X.; Audouin, L.; Verdu, J.; MonchyLeroy, C.; Prunier, V. Polym. Degrad. Stab. 2006, 91, 1598.

11. Colin, X.; Audouin, L.; Verdu, J.; Rozental-Evesque, M.; Rabaud, B.; Martin, F.; Bourgine, F. Polym. Eng. Sci. 2009, 49, 1429.

12. Fayolle, B.; Richaud, E.; Colin, X.; Verdu, J. J. Mater. Sci. 2008, 43, 6999.

13. Khelidj, N. Vieillissement d'Isolants de Câbles en Polyéthylene en Ambiance Nucléaire, Ph.D. thesis, ENSAM, Paris, France, Oct 2006.

14. Colin, X.; Teyssèdre, G.; Fois, M. In Handbook of Multiphase Polymer Systems; Boudenne, A., Ibos, L., Candau Y., Thomas, S., Eds.; John Wiley \& Sons Ltd: Chichester, 2011; Vol. 2/2, Chapter 21, p 797.

15. Carlsson, D. J.; Wiles, D. M. Macromolecules 1969, $2,587$.

16. Domke, W. D.; Steinke, H. J. Polym. Sci.: Polym. Chem. Ed. 1986, 24, 2701.

17. Colin, X.; Fayolle, B.; Audouin, L.; Verdu, J. Polym. Degrad. Stab. 2003, 80, 64.

18. Colin, X.; Audouin, L.; Verdu, J. Polym. Degrad. Stab. 2004, 86, 309.

19. François-Heude, A.; Richaud, E.; Guinault, A.; Desnoux, E.; Colin, X. J. Appl. Polym. Sci. 2015, 132, 41441. 
20. Hawkins, W. L.; Matreyek, W.; Winslow, F. H. J. Appl. Polym. Sci. 1959, 41, 1.

21. Baum, B. J. Appl. Polym. Sci. 1959, 2, 281.

22. Emanuel, N. M. Polym. Sci. USSR 1985, 27, 1505.

23. Gol'dberg, V. M.; Vidovskaya, L. A.; Zaikov, G. E. Polym. Degrad. Stab. 1988, 20, 93.

24. Wise, J.; Gillen, K. T.; Clough, R. L. Polym. Degrad. Stab. 1995, 49, 403

25. Jacobson, K. Polym. Degrad. Stab. 2007, 92, 448.

26. Richaud, E. Durabilité des Géotextiles en Polypropylène, Ph.D. thesis, Arts et Métiers ParisTech, Paris, France, Oct 2006.

27. Tireau, J. Propriétés à Long Terme des Gaines de Polyéthylène Haute Densité Utilisées pour les Ponts à Haubans, Ph.D. thesis, Arts et Métiers ParisTech, Paris, France, Jan 2011.

28. Carlsson, D. J.; Brousseau, R.; Wiles, D. M. Polym. Degrad. Stab. 1986, 15, 67.

29. Gugumus, F. Polym. Degrad. Stab. 2000, 67, 35.

30. Rivaton, A.; Cambon, S.; Gardette, J. L. Nucl. Instrum. Meth. Phys. Res. B 2007, 227, 343.

31. Pilichowski, J. F.; Lacoste, J.; Mallégol, J.; Michel, E.; Delor, F. Eur. Polym. J. 1997, 33, 1591.

32. Carlsson, D. J.; Brousseau, R.; Zang, C.; Wiles, D. M. Polym. Degrad. Stab. 1987, 17, 303.

33. Carlsson, D. J.; Lacoste, J. Polym. Degrad. Stab. 1991, 32, 377.

34. Richaud, E.; Farcas, F.; Fayolle, B.; Audouin, L.; Verdu, J. Polym. Test. 2006, 25, 829.

35. Gardette, J. L.; Lemaire, J. Polym. Photochem. 1986, 7, 409.

36. Ouldmetidji, Y.; Gonon, L.; Commereuc, S.; Verney, V. Polym. Test. 2001, 20, 765.

37. Mallégol, J.; Gonon, L.; Commereuc, S.; Verney, V. Prog. Org. Coat. 2001, 41, 171.

38. Ollier-Dureault, V.; Gosse, B. J. Appl. Polym. Sci. 1998, 70, 1221.

39. Delor, F.; Teissedre, G.; Baba, M.; Lacoste, J. Polym. Degrad. Stab. 1998, 60, 321.

40. Mailhot, B.; Jarroux, N.; Gardette, J. L. Polym. Degrad. Stab. 2000, 68, 321 .

41. Iring, M.; Tudos, F.; Fodor, Z.; Kelen, T. Polym. Degrad. Stab. 1980, 2, 143.

42. Fayolle, B.; Richaud, E.; Colin, X.; Verdu, J. Polym. Degrad. Stab. 2007, 92, 231.

43. Srivastava, D.; Kumar, P.; Mathur, G. N. Adv. Polym. Technol. 2004, 23, 59.
44. Weon, J. Polym. Degrad. Stab. 2010, 95, 14.

45. Khabbaz, F.; Albertsson, A. C.; Karlsson, S. Polym. Degrad. Stab. 1999, 63, 127.

46. Gardette, M.; Perthue, A.; Gardette, J. L.; Janecska, T.; Foldes, E.; Pukanszky, B.; Therias, S. Polym. Degrad. Stab. 2013, 98, 2383.

47. McMurry, H.; Thornton, V. Anal. Chem. 1952, 24, 318.

48. Shabani, A.; Colin, X.; Marque, G.; Monchy-Leroy, C. Rubber Chem. Technol. 2014, 87, 679.

49. Salvalaggio, M.; Bagatin, R.; Fornaroli, M.; Fanutti, S.; Palmery, S.; Battistel, E. Polym. Degrad. Stab. 2006, 91, 2775.

50. Venyaminov, S. Y.; Prendergast, F. G. Anal. Biochem. 1997, 248, 234.

51. Achimsky, L. Etude Cinétique de la Thermooxydation du Polypropylene, Ph.D. thesis, ENSAM, Paris, France, 1996.

52. Flett, M. S. C. Spectrochim. Acta 1962, 18, 1537.

53. Lacoste, J.; Carlsson, D. J. J. Polym. Sci. Part A: Polym. Chem. 1992, 30, 493.

54. Henman, T. J. In Developments in Polymer Degradation, Grassie, N., Ed.; ElsevierApplied Science: Barking, 1985; Vol. 6, pp 107-145.

55. Guyader Coquillat, M. Vieillissement des Propergols à Matrice Polybutadiène: Modélisation Cinétique de l'Oxydation, Ph.D. thesis, Arts et Métiers ParisTech, Paris, Sept 2007.

56. Tutorskii, I. A.; Sokolova, L. V.; Izyumnikov, A. L.; Novikov, S. V.; Troyanov, Ye. A.; Pestov, S. S.; Semenova, T. V. Vysokomol. Soyed. 1976, 3, 669.

57. Colin, X.; Audouin, L.; Verdu, J. Polym. Degrad. Stab. 2007, 92, 886.

58. Coquillat, M.; Verdu, J.; Colin, X.; Audouin, L.; Nevière, R. Polym. Degrad. Stab. 2007, 92, 1334.

59. Bolland, J. L.; Gee, G. Trans. Faraday Soc. 1946, 42, 236.

60. Adams, J. H. J. Polym. Sci. Part A: Polym. Chem. 1970, 8, 1077.

61. Nait-Ali, L. K.; Colin, X.; Bergeret, A. Polym. Degrad. Stab. 2011, 96, 236.

62. Calvert, J. G.; Pitts, J. N., Jr. In Photochemistry; John Wiley \& Sons Inc.: New York, 1966; pp 824-827.

63. Morrison, R. T.; Boyd, R. N. In Organic Chemistry, 6th ed.; Prentice-Hall: New York, 1992.

64. Kelter, P.; Mosher, M.; Scott, A. In Chemistry: The Practical Science; Houghton Mifflin Company: Boston, 2007. 